\title{
Capsaicin Inhibits Proliferation and Induces Apoptosis in Breast Cancer by Down-Regulating FBI-I-Mediated NF-kB Pathway
}

This article was published in the following Dove Press journal: Drug Design, Development and Therapy

\author{
Maojian Chen ${ }^{1} *$ \\ Chanchan $\mathrm{Xiao}^{2, *}$ \\ Wei Jiang ${ }^{3}$ \\ Weiping Yang ${ }^{4}$ \\ Qinghong Qin' \\ Qixing Tan (ID) \\ Bin Lian' \\ Zhijie Liang ${ }^{5}$ \\ Changyuan Wei'
}

'Department of Breast Surgery, Guangxi Medical University Cancer Hospital, Nanning, Guangxi 53002I, People's Republic of China; ${ }^{2}$ Department of Microbiology and Immunology, School of Medicine and Public Health, Jinan University, Guangzhou, Guangdong, 510632, People's Republic of China; ${ }^{3}$ Department of Medical Oncology, Guangxi Medical University Cancer Hospital, Nanning, Guangxi 53002I, People's Republic of China; ${ }^{4}$ Department of Ultrasound Diagnosis, Guangxi Medical University Cancer Hospital, Nanning, Guangxi 53002I, People's Republic of China; ${ }^{5}$ Department of Gland Surgery, The Fifth Affiliated Hospital of Guangxi Medical University \& The First People's Hospital of Nanning, Nanning, Guangxi 530022, People's Republic of China

*These authors contributed equally to this work
Background: As a natural compound extracted from a variety of hot peppers, capsaicin has drawn increasing attention to its anti-cancer effects against multiple human cancers including breast cancer. FBI-1 is a major proto-oncogene negatively regulating the transcription of many tumor suppressor genes, and plays a vital role in tumorigenesis and progression. However, whether FBI-1 is involved in capsaicin-induced breast cancer suppression has yet to be ascertained. This study aimed to investigate the effects of capsaicin on proliferation and apoptosis and its association with FBI-1 expression in breast cancer.

Methods: CCK-8 and morphological observation assay were employed to detect cell proliferation. Flow cytometry and TUNEL assay were conducted to detect cell apoptosis. RNA interference technique was used to overexpress or silence FBI-1 expression. qRT-PCR and/or Western blot analysis were applied to detect the protein expression of FBI-1, Ki-67, Bcl-2, Bax, cleaved-Caspase 3, Survivin and NF-kB p65. Xenograft model in nude mice was established to assess the in vivo effects.

Results: Capsaicin significantly inhibited proliferation and induced apoptosis in breast cancer in vitro and in vivo, along with decreased FBI-1, Ki-67, Bcl-2 and Survivin protein expression, increased Bax protein expression and activated Caspase 3. Furthermore, FBI-1 overexpression obviously attenuated the capsaicin-induced anti-proliferation and pro-apoptosis effect, accompanied with the above-mentioned proteins reversed, whereas FBI-1 silencing generated exactly the opposite response. In addition, as a target gene of FBI-1, NF- $\mathrm{BB}$ was inactivated by $\mathrm{p} 65$ nuclear translocation suppressed with capsaicin treatment, which was perceptibly weakened with FBI-1 overexpression or enhanced with FBI-1 silencing.

Conclusion: This study reveals that FBI-1 is closely involved in capsaicin-induced antiproliferation and pro-apoptosis of breast cancer. The underlying mechanism may be related to down-regulation of FBI-1-mediated NF- $\kappa$ B pathway. Targeting FBI-1 with capsaicin may be a promising therapeutic strategy in patients with breast cancer.

Keywords: capsaicin, breast cancer, proliferation, apoptosis, FBI-1, NF- $\kappa$ B

\section{Introduction}

Breast cancer is a common malignant tumor and the main cause of cancer-related death in women worldwide. ${ }^{1}$ The treatment modalities of breast cancer include surgery, radiotherapy, endocrine therapy, chemotherapy and targeted therapy. Chemotherapy is one of the most essential treatment strategies for breast cancer with high response rate. However, these are considered insufficient, with many patients who encounter tumor relapses and chemoresistance, or intolerable toxicity
Correspondence: Changyuan Wei Department of Breast Surgery, Guangxi Medical University Cancer Hospital, Nanning, Guangxi 53002I, People's Republic of China

$\mathrm{Tel} / \mathrm{Fax}+86077$ I 5308593

Email changyuanwei@gxmu.edu.cn 
yet. ${ }^{1,2}$ Thus, it is crucial to identify and develop other effective therapeutic agents to improve treatment efficacy of chemotherapy and decrease adverse effects in breast cancer.

Natural compounds and dietary products have been of great interest as anti-cancer agents with potent efficacy and low toxicity. ${ }^{3}$ Capsaicin (trans-8-methyl-N-vanillyl-6noneamide) is a class of vanilla amide alkaloid extracted from the chili peppers as its pungent component. ${ }^{4-6}$ In recent years, capsaicin is widely used as an analgesic agent. ${ }^{7}$ More recently, accumulating studies reported the anti-cancer activity and chemosensitization effect of capsaicin in multiple human cancers. ${ }^{4,8,9}$ It is generally supported that capsaicin suppresses tumorigenesis and progression through specifically binding to the transient receptor potential vanilloid 1 receptor (TRPV1) to promote a transient influx of $\mathrm{Ca}^{2+}$ and increase the concentration of $\mathrm{Ca}^{2+}$ in cancer cells, which lead to proliferation suppression and apoptosis promotion. ${ }^{10,11}$ Nevertheless, there is evidence that capsazepine, a TRPV1 antagonist, could not completely reverse the inhibitory effects of capsaicin on cancer cells, ${ }^{12}$ suggesting potent mechanisms other than TRPV1 signaling pathway, which need further investigation.

Factor that binds to the inductor of short transcripts of human immunodeficiency virus-1 (FBI-1), also known as Pokemon, ZBTB7A, LRF, OCZF, TIP, is one member of POK family negatively regulating the transcription of many tumor suppressor genes. ${ }^{13}$ FBI-1 is encoded by the ZBTB7 gene localized within chromosome 19p13.3. ${ }^{14,15}$ Accumulating evidences consider FBI-1 as a repressive transcriptional protein with proto-oncogenic activity, locating in the upstream of many tumor suppressors and protooncogenes for transcriptional regulation. ${ }^{16}$ In the year 2005, Meada et al found that FBI-1 overexpression could transcriptionally inhibit ARF expression, which led to p53 degradation and oncogenic transformation. On the contrary, FBI-1 depletion could inhibit the oncogene-mediated cellular transformation and induce cell senescence and apoptosis. ${ }^{15,16}$ Subsequently, a growing body of work confirmed that FBI-1 played a crucial role in tumorigenesis and progression. ${ }^{17-19}$ Several studies have reported that the expression of FBI-1 in breast cancer tissues is significantly higher than that in normal tissues and benign breast disease tissues, positively related to pathological grade, clinical stage and poor prognosis of breast cancer. ${ }^{20-22}$ Similarly, our recent study also confirmed that FBI-1 was involved in the occurrence and development of breast cancer, with high expression in breast cancer tissues, and breast cancer cell lines MCF-7 as well as MDA-MB-231. In addition, we found that FBI-1 overexpression promoted migration, invasion and metastasis of breast cancer. Conversely, FBI-1 silencing generated inhibitory effects. ${ }^{23}$ All results mentioned above suggest that targeting FBI-1 may be a promising therapeutic strategy for the prevention and treatment in breast cancer.

In view of the vital role of FBI-1 in the occurrence and development of breast cancer, this study aimed to investigate the effects of capsaicin on proliferation and apoptosis and its association with FBI-1 expression in breast cancer.

\section{Materials and Methods Reagents}

Capsaicin was purchased from MedChemexpress (Cat. No.: HY-10448; Purity: 99.01\%; Manmouth Junction, NJ, USA). Cell counting kit-8 (CCK-8) was purchased from Dojindo Laboratories (Kumamoto, Japan). Annexin VAPC/7-AAD apoptosis detection kit was purchased from BD Biosciences (San Diego, CA, USA). TUNEL assay kit was purchased from Beyotime Biotechnology Co., Ltd. (Shanghai, China). The primary antibodies against FBI-1 and GAPDH were obtained from Abcam (Cambridge, MA, USA). The primary antibodies against Ki-67, Bcl-2, Bax and Lamin B were obtained from Wanlei Biotechnology Co., Ltd. (Shenyang, China). The primary antibodies against cleaved-Caspase 3, Survivin and NF-кB p65 were obtained from Cell Signaling Technology (Danvers, MA, USA). The HRP-conjugated anti-rabbit IgG secondary antibody was obtained from EarthOx Life Sciences (Millbrae, CA, USA).

\section{Cell Culture}

Human breast cancer cell lines (MCF-7 and MDA-MB231) were obtained from the Cell Culture Bank of the Chinese Academy of Sciences (Shanghai, China) and cultured in Dulbecco's modified Eagle's medium (DMEM; Gibco, Rockville, MD, USA) containing 10\% fetal bovine serum (FBS; Gibco, Rockville, MD, USA), $100 \mu \mathrm{g} / \mathrm{mL}$ streptomycin (Hyclone, Logan, UT, USA), and $100 \mathrm{U} / \mathrm{mL}$ penicillin (Hyclone, Logan, UT, USA) in $5 \% \mathrm{CO}_{2}$ at $37{ }^{\circ} \mathrm{C}$.

\section{Cell Transfection}

The short hairpin-RNA (shRNA)-mediated RNA interference (RNAi) technique was used to overexpress or silence FBI-1 in breast cancer cells (MCF-7 and MDA-MB-231). 
The recombinant lentiviral particles (FBI-1-overexpression, FBI-1-silencing and corresponding negative control) carrying green fluorescent protein (GFP) were synthesized by Genechem Co., Ltd. (Shanghai, China). The target sequence of FBI-1-silencing was: GCAGCTGGACCT TGTAGATCA. The target sequence of corresponding negative control was: TTCTCCGAACGTGTCACGT. Cells were transfected with transfection reagents according to the manufacturer's instructions. The efficiency of FBI-1 overexpressing or silencing was assessed by inverted fluorescence microscopy (Olympus, Tokyo, Japan), quantitative real-time PCR (qRT-PCR), and Western blot. Finally, the successfully transfected cells were cultured in complete medium for further study.

\section{Cell Viability Assay}

Cells were seeded in 96 -well plates $\left(2 \times 10^{3}\right.$ cells/well $)$. After $24 \mathrm{~h}$ incubation to attachment, the cells were replaced by complete medium $(100 \mu \mathrm{L} /$ well $)$ with various concentrations of capsaicin $(0,50,100,150,200,250$ and $300 \mu \mathrm{mol} / \mathrm{L}$ ) for $24 \mathrm{~h}, 48 \mathrm{~h}$ and $72 \mathrm{~h}$, respectively. With dose determined by prior procedure, capsaicin $(150 \mu \mathrm{mol} /$ L) treatment alone or together with FBI-1 overexpression or silencing for $72 \mathrm{~h}$ was also administered. Then each well was added with $10 \mu \mathrm{L}$ CCK- 8 reagent and cultivated for $2 \mathrm{~h}$. Finally, cell optical density of each well was detected at $450 \mathrm{~nm}$ by enzyme immunoassay instrument.

\section{Morphological Observation Assay}

Cells were seeded in 6 -well plates $\left(2 \times 10^{5}\right.$ cells/well). After $24 \mathrm{~h}$ incubation to attachment, the cells were replaced by complete medium with various concentrations of capsaicin $(0,100$ and $150 \mu \mathrm{mol} / \mathrm{L})$. Besides, capsaicin $(150 \mu \mathrm{mol} / \mathrm{L})$ treatment alone or together with FBI-1 overexpression or silencing was also administered. After $72 \mathrm{~h}$, cell morphological changes were observed using an inverted microscope (Olympus, Tokyo, Japan).

\section{Flow Cytometry Analysis for Apoptosis}

Cells were seeded in 6 -well plates $\left(2 \times 10^{5}\right.$ cells/well). After $24 \mathrm{~h}$ incubation to attachment, the cells were given the same intervention as morphological observation assay. Capsaicintreated cells were harvested and resuspended in the binding buffer at a concentration of $5 \times 10^{5}$ cells $/ \mathrm{mL}$. Then the cells were stained with $5 \mu \mathrm{L}$ Annexin V-APC conjugate and $5 \mu \mathrm{L}$ 7-AAD solution at room temperature in the dark for $15 \mathrm{~min}$. Finally, the cell apoptosis rate was detected by a flow cytometer (BD Biosciences, San Jose, CA, USA).

\section{Quantitative Real-Time PCR}

Total RNA was extracted from cells using the Trizol Reagent Kit (Invitrogen, California, USA). Then the total RNA was reverse transcribed into complementary DNA (cDNA) using Reverse Transcriptase kit (Takara, Kusatsu, Japan). Followed, the cDNA was used as template to determine the level of mRNA expression. The sequences of the primers were as follows: FBI-1 5'-TTGCCAAAG ATACCTGCTGA-3' (Forward), 5'-AAACCCCAAACAA CCAAACA-3' (Reverse); GAPDH 5'-AGAAGGCTGG GGCTCATTTG-3' (Forward), 5'-AGGGGCCATCCACA GTCTTC-3' (Reverse). The quantitative real-time PCR reactions were performed on the Mx3000P System (Agilent Technologies, CA, USA) using SYBR Premix Ex TaqTM II real-time PCR kit (Takara, Kusatsu, Japan). All samples were amplified in triplicate in one assay run simultaneously. GAPDH was regarded as the internal control to normalize the results.

\section{Western Blot Analysis}

The whole-cell proteins were extracted from the harvested cells or the fresh xenograft tumor tissues using cold RIPA lysis buffer (Solarbio, Beijing, China) supplemented with protease inhibitor cocktail (Solarbio, Beijing, China). The nuclear or cytoplasmic protein was obtained using the nuclear and cytoplasmic protein extraction kit (Wanlei Biotechnology Co., Ltd., Shenyang, China) according to the manufacturer's protocol. Protein concentrations were measured by the bicinchoninic acid method. An aliquot of protein lysate was separated by SDS-PAGE and transferred onto PVDF membranes (Solarbio, Beijing, China). After being blocked by 5\% non-fat milk for 1 hour at room temperature, the membranes were incubated overnight at $4{ }^{\circ} \mathrm{C}$ with primary antibodies against FBI-1 (1:10000), Ki67 (1:500), Bcl-2 (1:500), Bax (1:500), cleaved-Caspase 3 (1:1000), Survivin (1:1000), NF-אB p65 (1:1000), GAPDH (1:10000) and Lamin B (1:500). After incubation with HRP-conjugated anti-rabbit IgG secondary antibody, the protein expression was analyzed using enhanced chemiluminescence system ChemiDoc MP (BioRad, Hercules, CA, USA).

\section{In vivo Study}

Female BALB/c athymic nude mice (4-5 weeks of age, 14-16 g) were purchased from Guangxi Medical University Experimental Animal Center and maintained under specific pathogen-free condition. All procedures 
involving animals were approved by the Guangxi Medical University Experimental Animal Committee, and were performed in accordance with the Institutional Animal Welfare Guidelines set by Guangxi Medical University. After harvested and resuspended in PBS, a suspension $\left(200 \mu \mathrm{L}\right.$ ) containing $1 \times 10^{7}$ MDA-MB-231 cells (with FBI-1-overexpression or FBI-1-silencing or corresponding negative control) were subcutaneously injected into left side of flank area of each mouse ( $\mathrm{n}=3$ mice per group). When in situ tumor growth appeared around about 100 $\mathrm{mm}^{3}$ after inoculation, experimental mice were administered intraperitoneally with capsaicin $\left(10 \mathrm{mg} / \mathrm{kg},{ }^{24}\right.$ once in three days), whereas control mice received an equal volume of sterile phosphate buffered saline (PBS) at the corresponding time point. The body weight and the tumor size of each mouse were measured every three days. The tumor volume was calculated using the formula: volume $\left(\mathrm{mm}^{3}\right)=$ length $(\mathrm{mm}) \times$ width $(\mathrm{mm})^{2} / 2$. After the 21 st day of capsaicin treatment, all mice were euthanized and their tumor nodules were enucleated, photographed, weighed and harvested for further study.

\section{TUNEL Assay}

Harvested fresh tumor tissues were fixed with $4 \%$ paraformaldehyde, embedded in paraffin and sectioned of 4 $\mu \mathrm{m}$ thick. Followed, the slides were deparaffinized, rehydrated, and cooked with citrate buffer $(\mathrm{pH}$ 6.0) under high pressure for antigen retrieval. According to the manufacturer's protocol, the slides were subsequently stained with TUNEL test solution and cell nuclei were counterstained with 4,6-diamidino-2-phenylindole (DAPI). Finally, the TUNEL positive cells (red) and cell nuclei (blue) were captured under a fluorescence microscope (Olympus, Tokyo, Japan) and quantified using Image-Pro Plus 5.0 software (Media Cybernetics, Maryland, MD, USA).

\section{Statistical Analysis}

All experiments in our study were independently performed in triplicate and data were presented as means \pm standard deviation (SD). Considering the small sample size in our study, Permutation test was used for statistical comparison. All data analyses were conducted using SPSS 17.0 software (SPSS Inc, Chicago, USA) or R software (Version 3.6.3). A $p$-value less than 0.05 was considered of statistical significance.

\section{Results}

\section{Capsaicin Inhibits Proliferation of Breast Cancer Cells}

We initially investigated whether capsaicin inhibited proliferation of breast cancer cells. As shown in Figure 1A, the CCK-8 results showed that capsaicin significantly inhibited the cell viability of both MCF-7 and MDAMB-231 cells in a dose- and time-dependent manner. The calculated half-maximal inhibitory concentrations (IC50) indicated that the non-triple-negative breast cancer cell line MCF-7 showed more sensitive to capsaicin as compared with triple-negative breast cancer cell line MDAMB-231 (Figure 1A). The morphological observation assay showed that both MCF-7 and MDA-MB-231 cells treated with capsaicin presented distinct morphological changes, including shrinking, shedding, poor adhesion and lifeless, which became more obvious as the dose of capsaicin increased (Figure 1B). These data suggest that capsaicin exerts a significant anti-proliferation effect in breast cancer cells.

\section{Capsaicin Induces Apoptosis of Breast Cancer Cells}

Subsequently, flow cytometry analysis was performed to investigate whether capsaicin induced apoptosis of breast cancer cells. As shown in Figure 1C, capsaicin significantly promoted apoptotic death of MCF-7 and MDAMB-231 cells in a dose-dependent manner. These data suggest that capsaicin elicits a significant pro-apoptosis effect in breast cancer cells.

\section{Capsaicin Suppresses the Expression of FBI-I in Breast Cancer Cells}

The above results prompted us to further explore the underlying mechanisms of capsaicin-induced anti-proliferation and pro-apoptosis effects in breast cancer cells. Previous studies including ours have demonstrated that FBI-1 plays a vital role in tumorigenesis and progression, ${ }^{16,19,23}$ suggesting that pharmacological inhibition of FBI-1 may be a promising therapeutic strategy in breast cancer. Thus, we sought to investigate whether capsaicin treatment could inhibit the expression of FBI-1 in our study. Western blot analysis was performed and the obtained results showed that the expression of FBI-1 was significantly down-regulated in MCF-7 and MDA-MB-231 cells after capsaicin administration, enhanced with the dose increment (Figure 2). These 

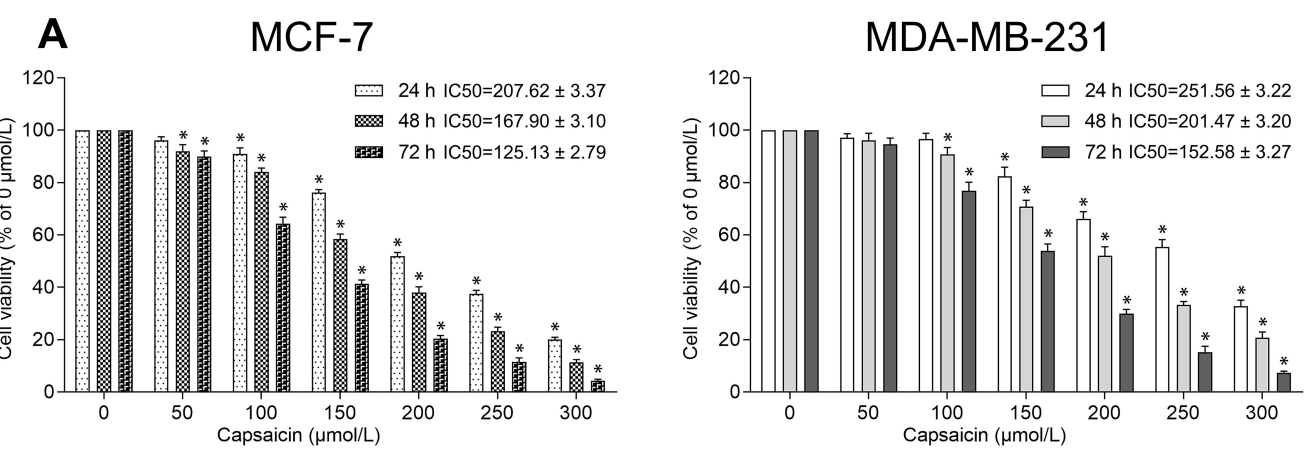

B

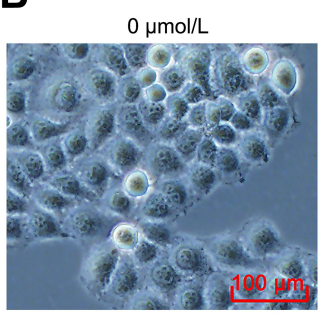

MCF-7
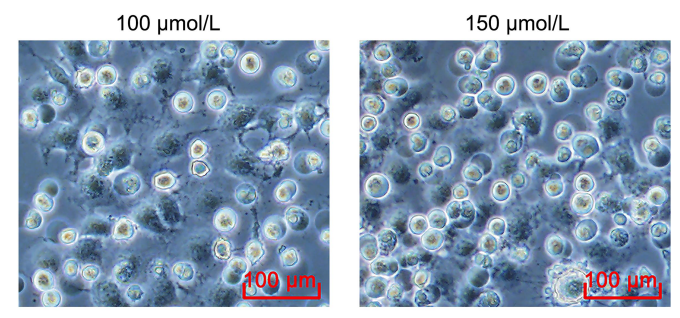

MDA-MB-231
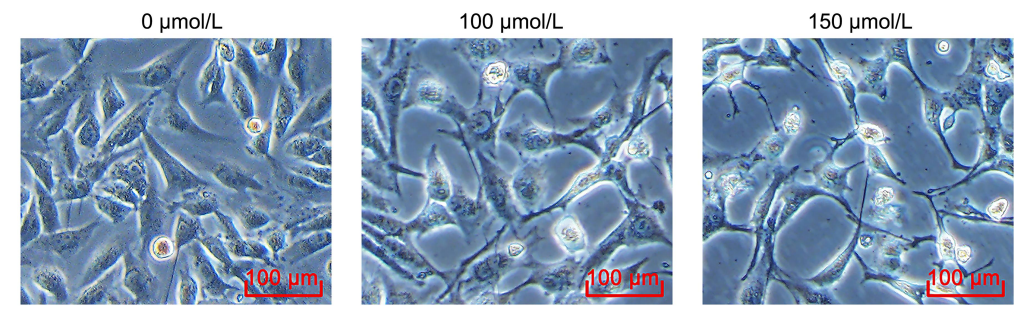

C

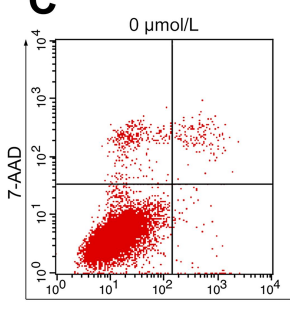

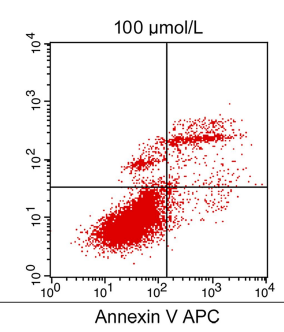

MCF-7
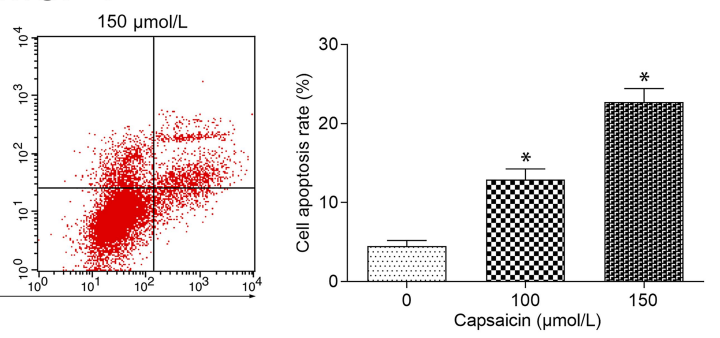

MDA-MB-231
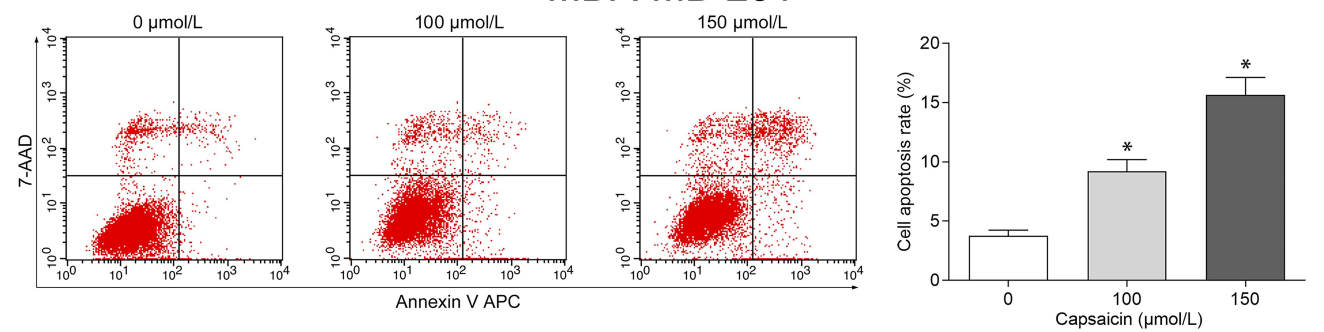

Figure I Capsaicin inhibits proliferation and induces apoptosis of breast cancer cells. (A) Cells were treated with capsaicin (0, 50, I00, I50, 200, 250 and 300 $\mu$ mol/L) for $24 \mathrm{~h}, 48 \mathrm{~h}$ and $72 \mathrm{~h}$, respectively. The cell viability was detected by CCK-8 assay. Data are presented as means \pm SD, $* p<0.05$ vs Control $(0 \mu \mathrm{mol} / \mathrm{L})$. (B) Cells were treated with capsaicin $(0,100$ and $150 \mu \mathrm{mol} / \mathrm{L})$ for $72 \mathrm{~h}$. The cell morphological changes were observed using an inverted microscope (scale bar $100 \mu \mathrm{m})$. (C) Cells were treated with capsaicin $(0,100$ and I $50 \mu \mathrm{mol} / \mathrm{L})$ for $72 \mathrm{~h}$. The cell apoptosis rate was detected by flow cytometry. Data are presented as means $\pm \mathrm{SD}$, * $p<0.05 \mathrm{vs}$ Control $(0 \mu \mathrm{mol} / \mathrm{L})$. 

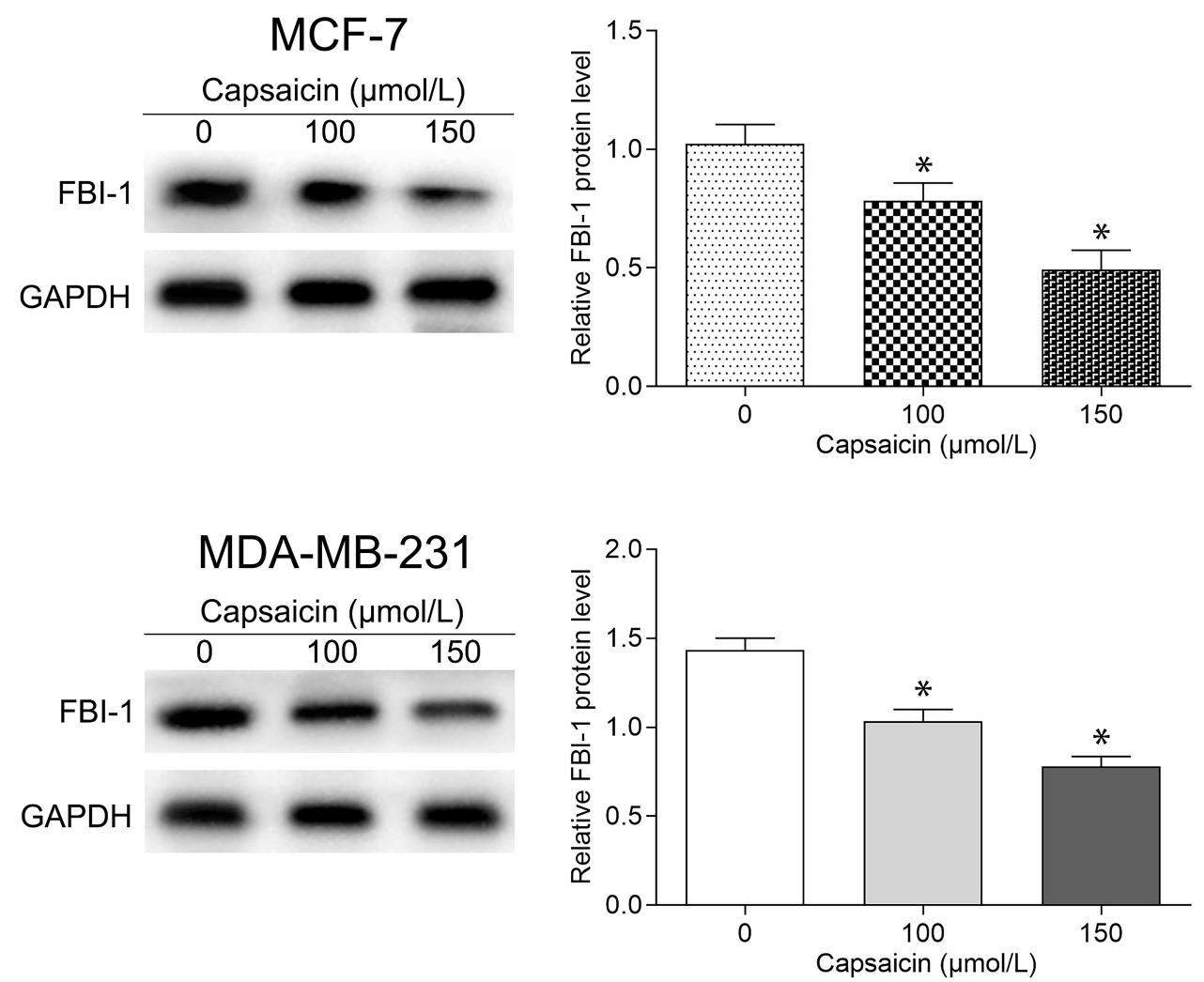

Figure 2 Capsaicin suppresses the expression of FBI-I in breast cancer cells. Cells were treated with capsaicin (0, I00 and I50 $\mu$ mol/L) for 72 h. The protein level of FBI-I was detected by Western blot. Data are expressed as means $\pm \mathrm{SD}, * p<0.05$ vs Control $(0 \mu \mathrm{mol} / \mathrm{L})$.

data suggest that the anti-proliferation and pro-apoptosis activities of capsaicin in breast cancer cells may be associated with the suppression of FBI-1 expression.

\section{FBI-I Overexpression Attenuates the Capsaicin-Induced Anti-Proliferation and Pro-Apoptosis Effects in Breast Cancer Cells}

To clarify the relationship between FBI-1 and the cytotoxic effects of capsaicin in breast cancer cells. We up-regulated the expression of FBI-1 via recombinant FBI-1 overexpression lentiviral particles transfection. As shown in Figure $3 \mathrm{~A}-\mathrm{C}$, the transfection experiments indicated the successful FBI-1 overexpressing efficiency in MCF-7 and MDA-MB231 cells. The subsequent results from CCK-8 assay, morphological observation assay and flow cytometry analysis showed that FBI-1 overexpression perceptibly triggered proliferation and repressed apoptosis of MCF-7 and MDA-MB231 cells (Figure 3D-F). Moreover, FBI-1 overexpression partially abrogated the capsaicin-induced effects on proliferation suppression and apoptosis promotion (Figure 3D-F). Based on the above observations, we further examined the levels of typical reported proliferation- and apoptosis-related proteins (Ki-67, Bcl-2, Bax, cleaved-Caspase 3 and Survivin). As expected, the results from Western blot analysis showed that capsaicin treatment significantly down-regulated the expression of Ki-67, Bcl-2 and Survivin, and up-regulated the expression of Bax and cleaved-Caspase 3 in MCF-7 and MDA-MB-231 cells (Figure 4). Conversely, FBI-1 overexpression significantly up-regulated the expression of Ki-67, Bcl-2 and Survivin, and down-regulated the expression of Bax and cleaved-Caspase 3 (Figure 4). Besides, FBI-1 overexpression perceptibly attenuated the effects of capsaicin on the above-mentioned proteins (Figure 4). Taken together, these data suggest that capsaicin antagonizes FBI-1 during the process of its anti-proliferation and pro-apoptosis in breast cancer cells.

\section{FBI-I Silencing Enhances the Capsaicin- Induced Anti-Proliferation and Pro- Apoptosis Effects in Breast Cancer Cells} In order to verify the role of FBI-1 in capsaicin-induced cytotoxic effects in breast cancer cells, we down-regulated the expression of FBI-1 via recombinant FBI-1 silencing 

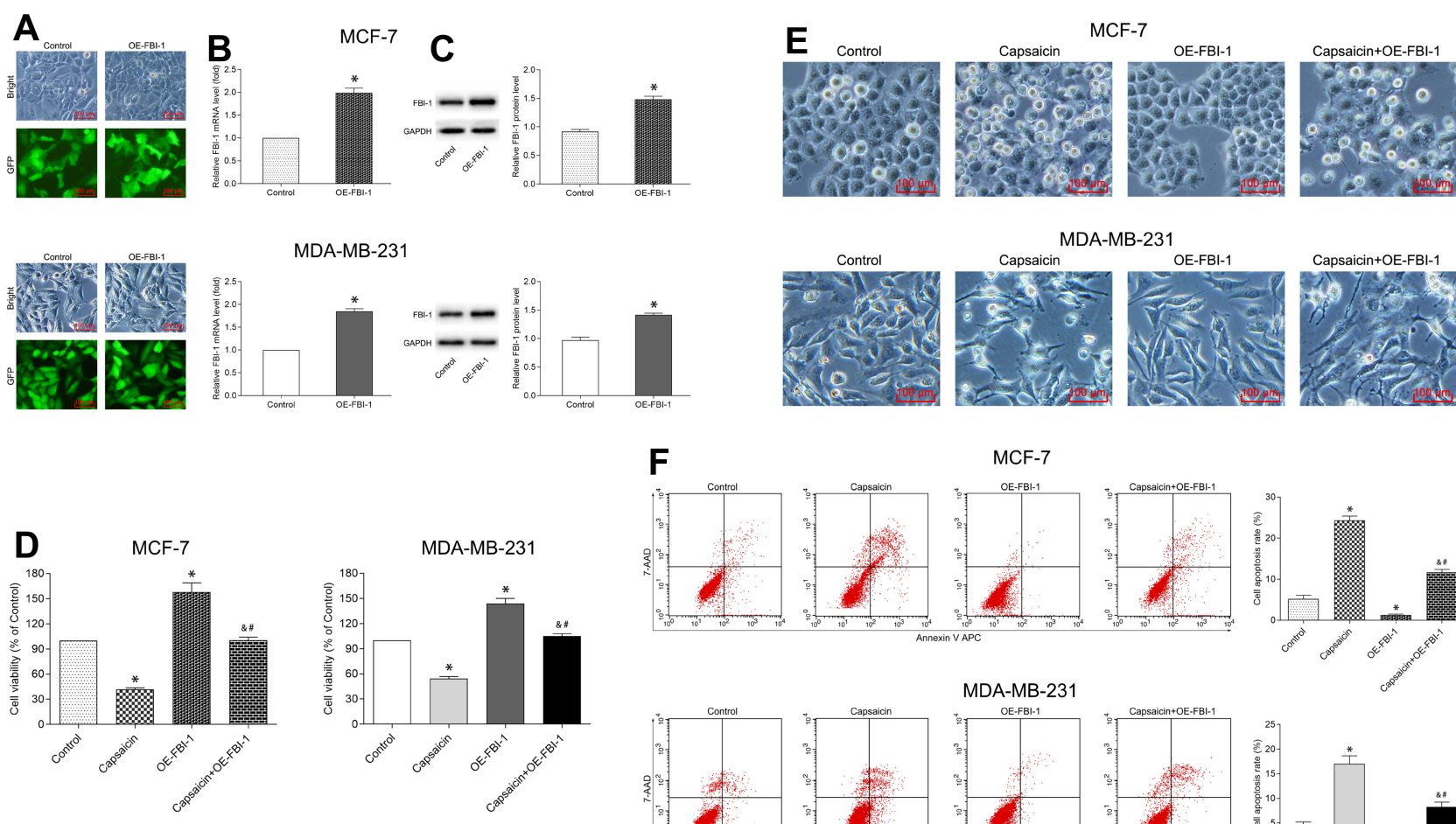

$\mathbf{F}$
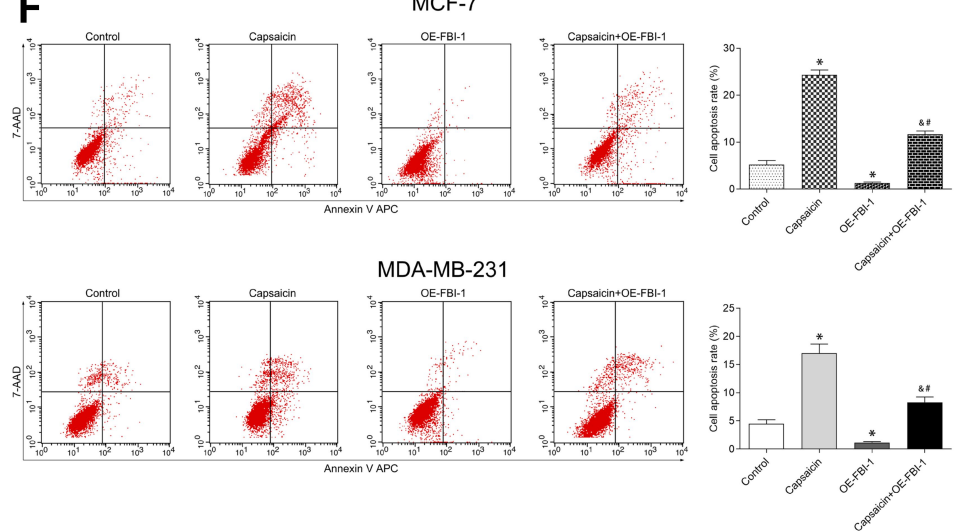

Figure $3 \mathrm{FBI}$-I overexpression attenuates the capsaicin-induced anti-proliferation and pro-apoptosis effects in breast cancer cells. (A-C) Cells were transfected with recombinant FBI-I-overexpression lentiviral particles or corresponding negative control vectors, respectively. The efficiency of FBI-I overexpressing was assessed by inverted fluorescence microscopy, qRT-PCR, and Western blot. Scale bar $100 \mu \mathrm{m}$, or data are presented as means \pm SD, $* p<0.05$ vs Control. (D) Cells were treated with capsaicin alone (I50 $\mu$ mol/L) or together with FBI-I overexpression for $72 \mathrm{~h}$. The cell viability was detected by CCK-8 assay. Data are presented as means \pm SD, ${ }^{*} p<0.05$ vs Control; ${ }^{*}<<0.05$ vs Capsaicin; ${ }^{\#} p<0.05$ vs OE-FBI-I. (E) Cells were treated with capsaicin alone ( $150 \mu \mathrm{mol} / \mathrm{L})$ or together with $\mathrm{FBI}-\mathrm{I}$ overexpression for $72 \mathrm{~h}$. The cell morphological changes were observed using an inverted microscope (scale bar $100 \mu \mathrm{m})$. (F) Cells were treated with capsaicin alone ( $150 \mu \mathrm{mol} / \mathrm{L})$ or together with FBI-I overexpression for $72 \mathrm{~h}$. The cell apoptosis rate was detected by flow cytometry. Data are presented as means \pm SD, ${ }^{*} p<0.05$ vs Control; ${ }^{\circledR} p<0.05$ vs Capsaicin; ${ }^{\#} p<0.05$ vs OE-FBI-I.

lentiviral particles transfection. As shown in Figure 5A-C, the transfection experiments indicated the successful FBI1 silencing efficiency in MCF-7 and MDA-MB-231 cells. The subsequent results from CCK-8 assay, morphological observation assay and flow cytometry analysis showed that FBI-1 silencing perceptibly inhibited proliferation and induced apoptosis of MCF-7 and MDA-MB-231 cells (Figure 5D-F). Strikingly, FBI-1 silencing markedly enhanced the capsaicin-induced effects on proliferation inhibition and apoptosis promotion (Figure 5D-F). Furthermore, we observed that FBI-1 silencing significantly down-regulated the expression of Ki-67, Bcl-2 and Survivin, and up-regulated the expression of Bax and cleaved-Caspase 3 (Figure 6). Besides, FBI-1 silencing perceptibly enhanced the effects of capsaicin on the above-mentioned proteins (Figure 6). Altogether, these data further confirm the vital role of FBI-1 during the process of capsaicin-induced anti-proliferation and proapoptosis in breast cancer cells.

\section{FBI- $I$ is Involved in Capsaicin-Induced Anti-Proliferation and Pro-Apoptosis in Breast Cancer in vivo}

Next, to further assess the biological relevance of the obtained results in vitro, in vivo study with capsaicin treatment alone or together with FBI-1 overexpression or silencing was performed. As seen from parts A, B and C of Figure 7, the volume and weight of formed tumors were significantly reduced with capsaicin treatment, which were perceptibly weakened when combined with FBI-1 overexpression. In contrast, the capsaicin-induced tumor growth inhibition was perceptibly enhanced with FBI-1 silencing. In addition, neither apparent loss of appetite, nausea, vomiting nor significant body weight changes in the mice were observed throughout the treatment (Figure 7D). Further investigation showed that capsaicin treatment significantly induced apoptosis (Figure 7E). Nevertheless, FBI-1 overexpression was found to attenuate capsaicininduced apoptosis, and FBI-1 silencing enhanced apoptosis (Figure 7E). Moreover, we noted that capsaicin treatment 

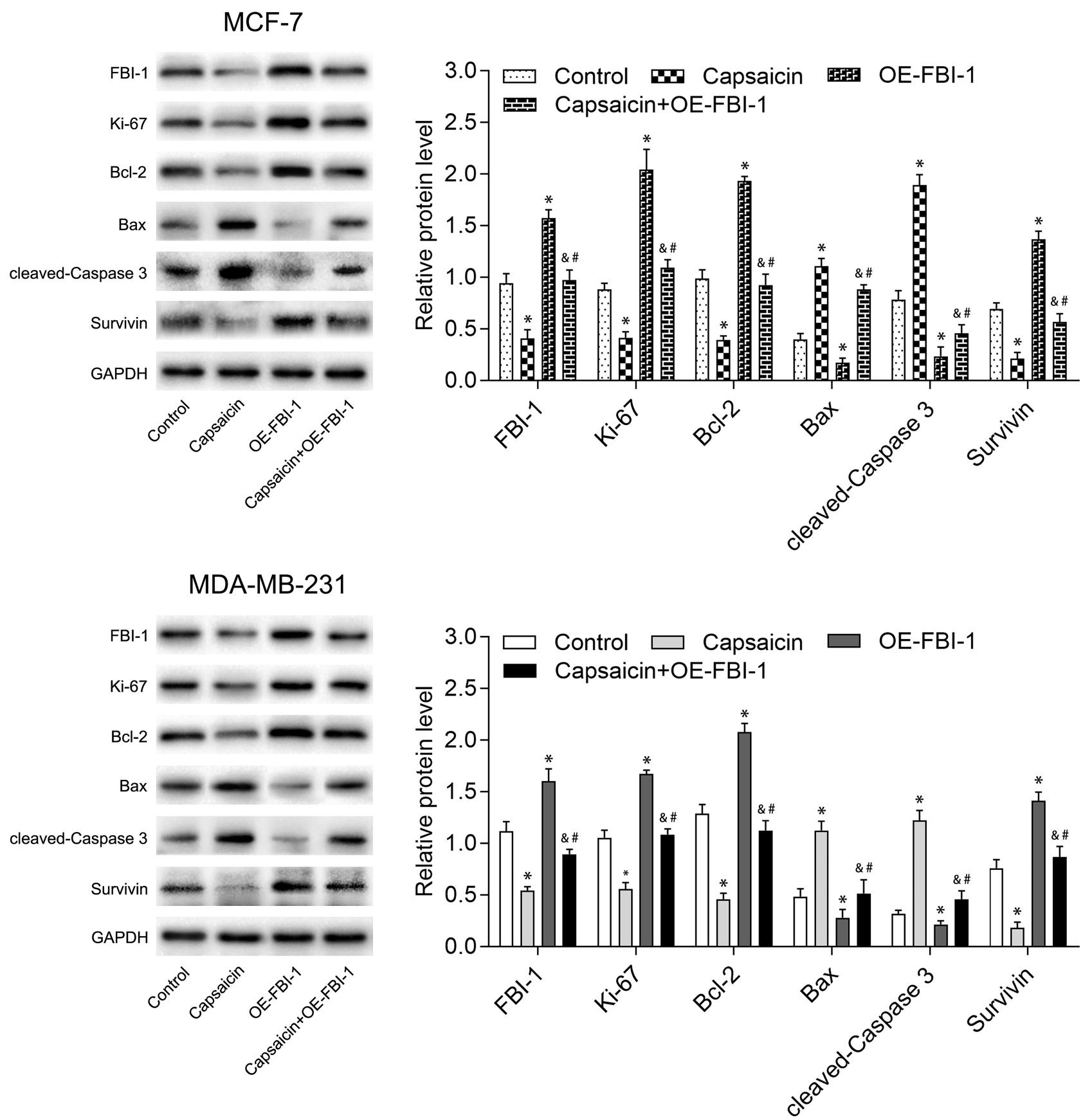

Figure $4 \mathrm{FBI}-\mathrm{I}$ overexpression weakens the capsaicin-induced effects on typical reported proliferation- and apoptosis-related proteins in breast cancer cells. Cells were treated with capsaicin alone (I50 $\mathrm{mol} / \mathrm{L})$ or together with FBI-I overexpression for $72 \mathrm{~h}$. The protein levels of FBI-I, Ki-67, Bcl-2, Bax, cleaved-Caspase 3 and Survivin were detected by Western blot. Data are presented as means \pm SD, ${ }^{*} p<0.05$ vs Control; ${ }^{{ }} p<0.05$ vs Capsaicin; ${ }^{*} p<0.05$ vs OE-FBI-I.

significantly down-regulated the expression of Ki-67, Bcl-2 and Survivin, and up-regulated the expression of Bax and cleaved-Caspase 3 in formed tumors (Figure 7F). However, the effects of capsaicin on the above-mentioned proteins were perceptibly weakened with FBI-1 overexpression or enhanced with FBI-1 silencing (Figure 7F). Collectively, the above data suggest that FBI-1 is involved in capsaicin-induced anti-proliferation and pro-apoptosis in breast cancer in vivo.

\section{Capsaicin-Induced FBI-I Down-} Regulation Suppresses NF-kB Activation in Breast Cancer in vitro and in vivo

Finally, we sought to address the signaling pathways by which capsaicin exerted the cytotoxic effects in breast cancer. As aforementioned, capsaicin significantly suppressed the expression of FBI-1 in breast cancer (Figures 2, 4, 6 and 7F). Our 

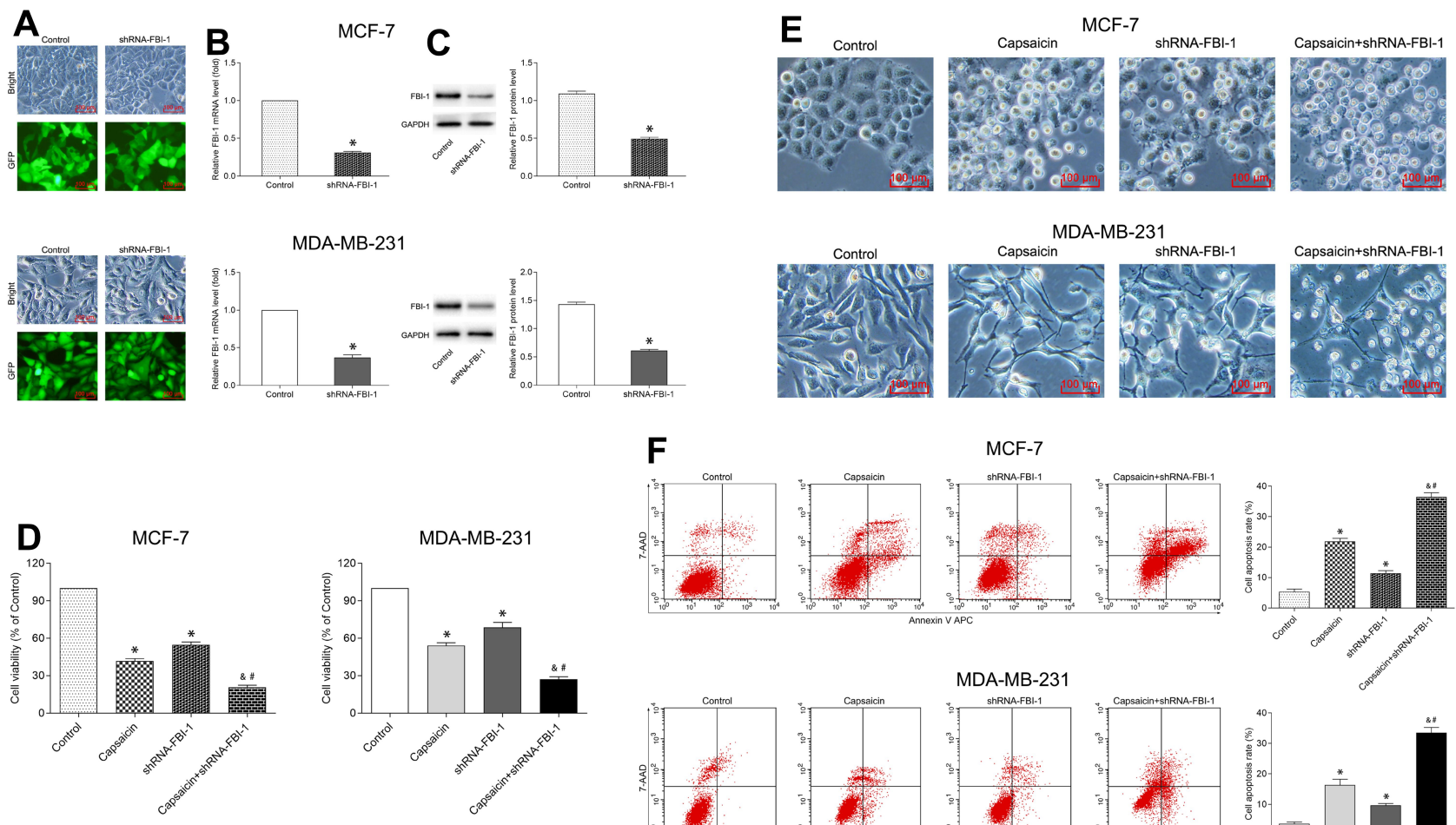

\section{$\mathbf{F}$}
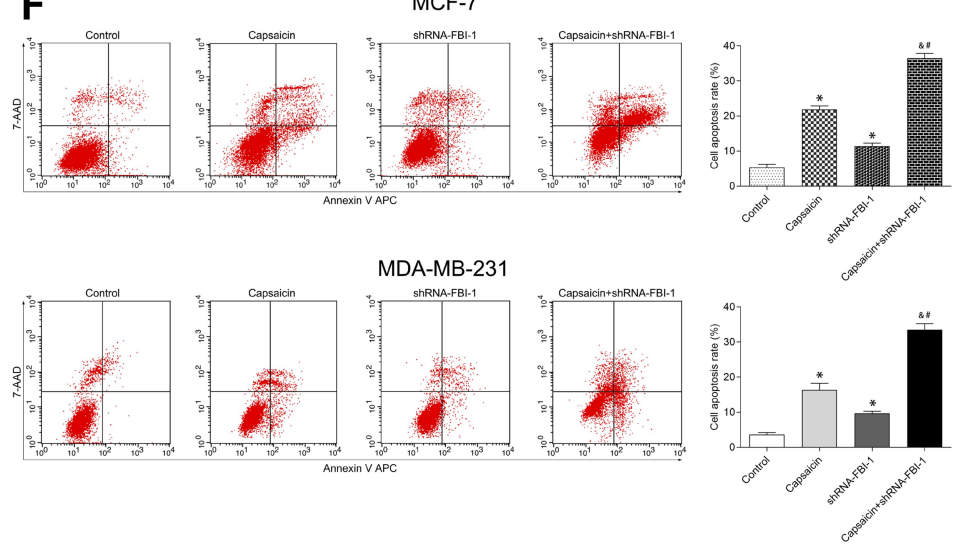

Figure $5 \mathrm{FBI}-\mathrm{I}$ silencing enhances the capsaicin-induced anti-proliferation and pro-apoptosis effects in breast cancer cells. (A-C) Cells were transfected with recombinant FBI-I-silencing lentiviral particles or corresponding negative control vectors, respectively. The efficiency of FBI-I silencing was assessed by inverted fluorescence microscopy, qRT-PCR, and Western blot. Scale bar $100 \mu \mathrm{m}$, or data are presented as means \pm SD, ${ }^{*} p<0.05$ vs Control. (D) Cells were treated with capsaicin alone (I50 $\mu$ mol/L) or together with FBI-I silencing for $72 \mathrm{~h}$. The cell viability was detected by CCK- 8 assay. Data are presented as means $\pm S D,{ }^{*} p<0.05$ vs Control; ${ }^{\&} p<0.05$ vs Capsaicin; ${ }^{\#} p<0.05$ vs shRNA-FBI-I. (E) Cells were treated with capsaicin alone $(I 50 \mu \mathrm{mol} / \mathrm{L})$ or together with $\mathrm{FBI}-\mathrm{I}$ silencing for $72 \mathrm{~h}$. The cell morphological changes were observed using an inverted microscope (scale bar $100 \mu \mathrm{m})$. (F) Cells were treated with capsaicin alone $(150 \mu \mathrm{mol} / \mathrm{L})$ or together with FBI-I silencing for $72 \mathrm{~h}$. The cell apoptosis rate was detected by flow cytometry. Data are presented as means \pm SD, ${ }^{*} p<0.05$ vs Control; ${ }^{*} p<0.05$ vs Capsaicin; ${ }^{\#} p<0.05$ vs shRNA-FBI-I.

previously published data indicated that FBI-1 promoted migration, invasion and metastasis of breast cancer through NF- $\kappa \mathrm{B}$ signaling pathway. ${ }^{23}$ Along these lines, we wondered whether capsaicin-induced FBI-1 down-regulation modulated $N F-\kappa B$ signaling pathway. To this end, we examined NF- $\kappa B$ activity by analysis of NF-kB p65 level in nucleus and cytoplasm with capsaicin treatment alone or together with FBI-1 overexpression or silencing. As shown in Figure 8, Western blot analysis showed that the expression of NF- $\mathrm{B}$ p 65 was relatively higher in cytoplasm, and conversely lower in nucleus with capsaicin treatment compared to the control group, indicating that capsaicin treatment significantly suppressed NF- $\mathrm{B}$ activation by inhibiting p65 nuclear translocation in vitro (MCF-7, MDA-MB-231 cells) and in vivo. Noteworthily, the suppressive effect of capsaicin on NF- $\mathrm{BB}$ activity was perceptibly weakened with FBI-1 overexpression or enhanced with FBI-1 silencing. Collectively, these data suggest that the anti-proliferation and pro-apoptosis activities of capsaicin in breast cancer may be associated with inhibition of FBI-1-mediated NF- $\mathrm{B}$ signaling pathway.

\section{Discussion}

Epidemiological and experimental evidences confirmed the prevention and treatment effects of many dietary products on human cancers. ${ }^{25}$ In recent years, as a natural compound extracted from hot peppers, capsaicin has been indicated anti-cancer activity on many types of human cancers through suppressing proliferation, arresting cell cycle, inducing apoptosis, inhibiting invasion and metastasis, etc. ${ }^{4,8}$ For example, Zhu et al found that capsaicin suppressed activity of prostate cancer stem cell through Wnt/ $\beta$-Catenin pathway. ${ }^{26}$ In bladder cancer cells, the inhibitive effects on growth and migration of capsaicin were found to be associated with SIRT1 targeting and down regulation of FOXO3a-mediated pathway. ${ }^{27,28}$ In 

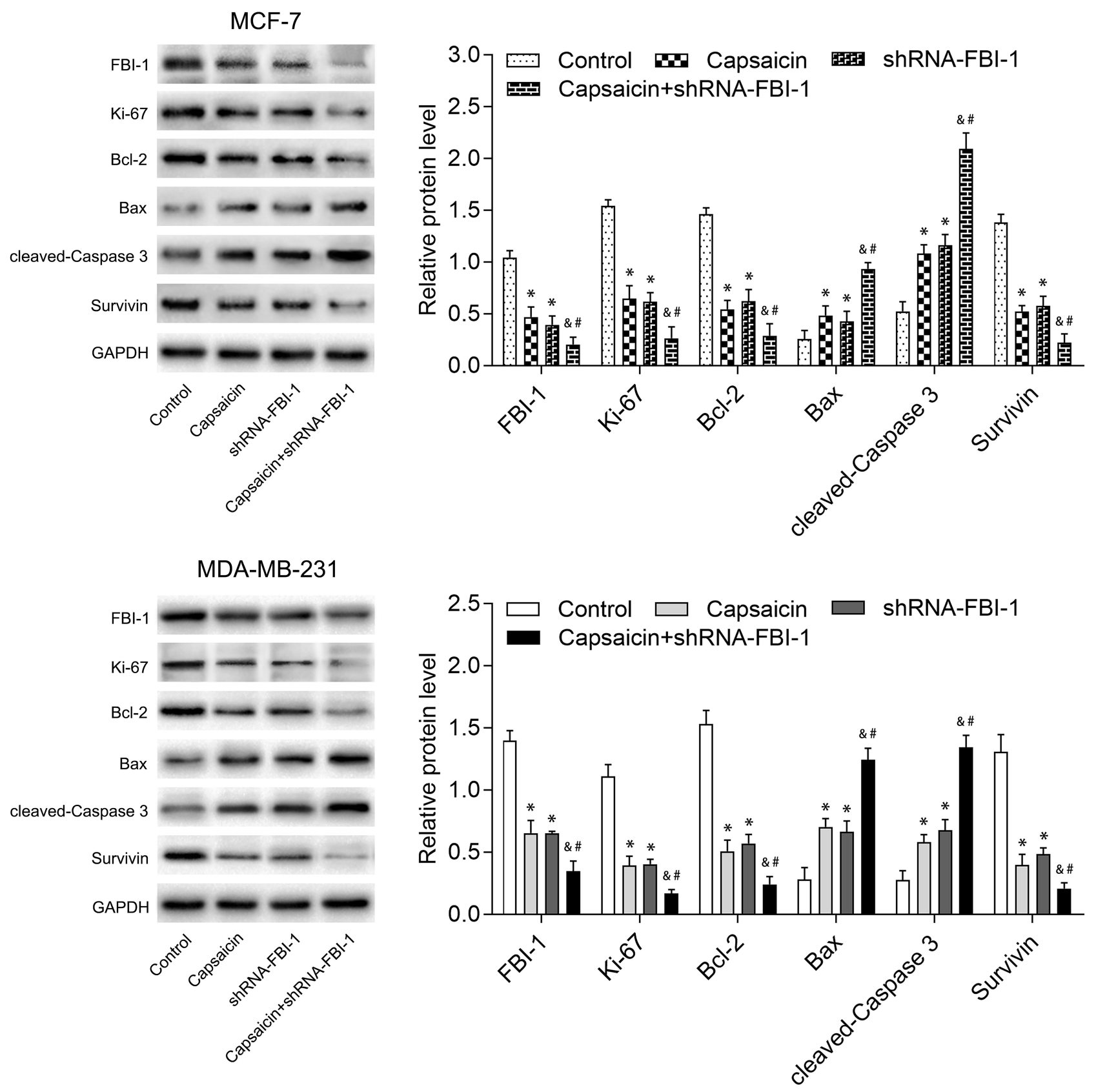

Figure $6 \mathrm{FBI}-\mathrm{I}$ silencing enhances the capsaicin-induced effects on typical reported proliferation- and apoptosis-related proteins in breast cancer cells. Cells were treated with capsaicin alone ( $150 \mu \mathrm{mol} / \mathrm{L}$ ) or together with FBI-I silencing for $72 \mathrm{~h}$. The protein levels of FBI-I, Ki-67, Bcl-2, Bax, cleaved-Caspase 3 and Survivin were detected by Western blot. Data are presented as means \pm SD, ${ }^{*} p<0.05$ vs Control; ${ }^{\&} p<0.05$ vs Capsaicin; ${ }^{*} p<0.05$ vs shRNA-FBI-I.

combination with 3,3'-diindolylmethane, capsaicin suppressed the proliferation and induced apoptosis of colorectal cancer cells through activating the transcriptional activity of NF- $\mathrm{kB}$ and $\mathrm{p} 53$, and modulating the expression of their downstream target genes. ${ }^{29}$ In colon cancer cells, capsaicin induced apoptosis through generating reactive oxygen species and disrupting mitochondrial transmembrane potential. ${ }^{30}$ Recent investigations also reported the anti-growth effect of capsaicin in breast cancer was associated with G0/G1-phase cell cycle arrest, increased level of apoptosis. ${ }^{31,32}$ Similarly, our results showed that capsaicin significantly suppressed the proliferation and induced apoptosis of breast cancer in vitro and in vivo. Additionally, neither apparent loss of appetite, nausea, vomiting nor significant body weight changes in the mice were observed throughout the treatment. Consistent with 

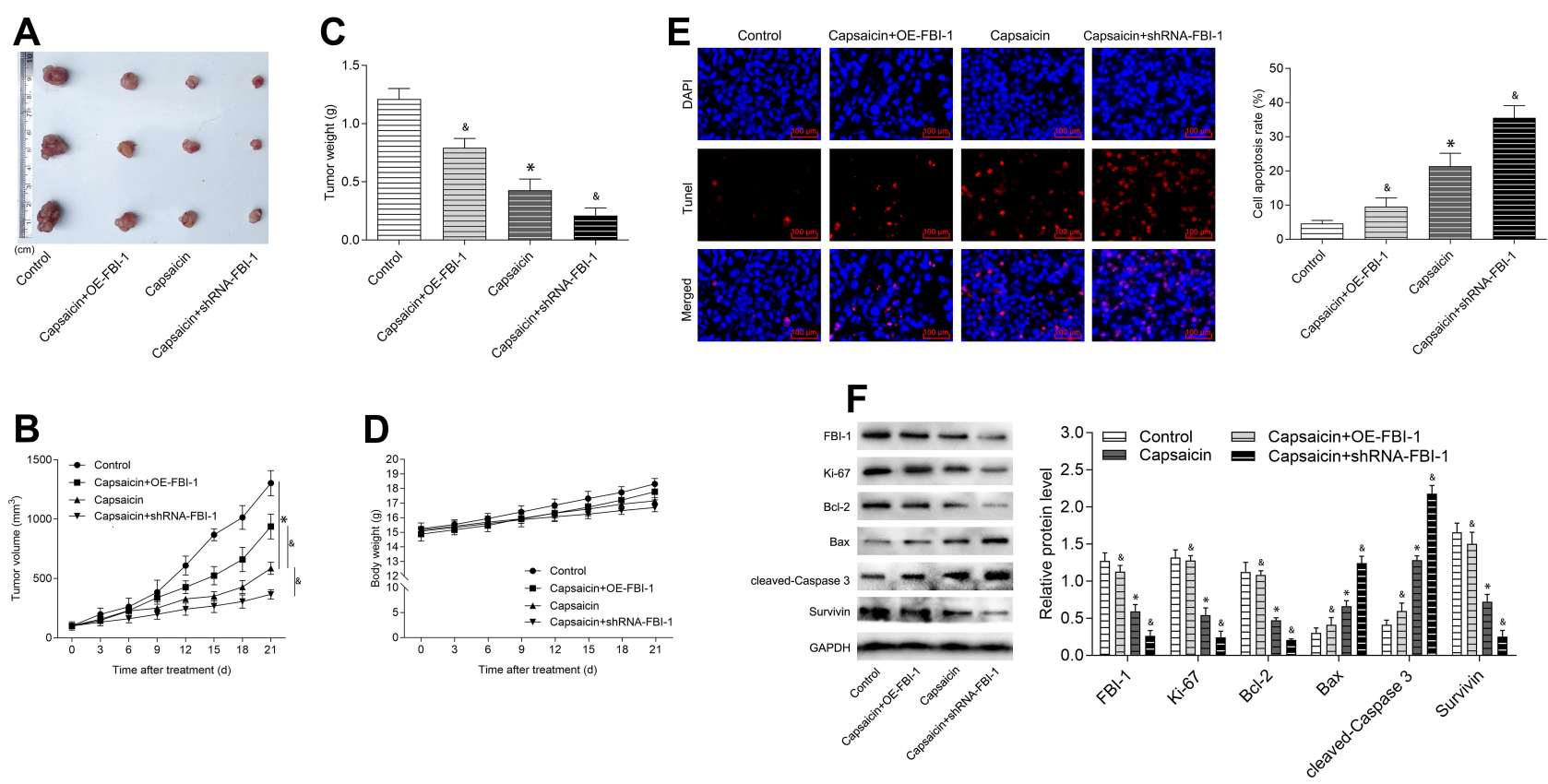

Figure $7 \mathrm{FBI}-\mathrm{I}$ is involved in capsaicin-induced anti-proliferation and pro-apoptosis in breast cancer in vivo. Female BALB/c athymic nude mice bearing MDA-MB-23I cells (with $\mathrm{FBI}-\mathrm{I}$-overexpression or $\mathrm{FBI}-\mathrm{I}$-silencing or corresponding negative control) were administered intraperitoneally with capsaicin ( $10 \mathrm{mg} / \mathrm{kg}$, once in three days) for $2 \mathrm{I}$ days. (A) The formed tumors were enucleated and photographed after the 21 st day of capsaicin treatment. (B) The formed tumor volume changes were recorded during the experimental period. (C) The formed tumors were weighed after the 21 st day of capsaicin treatment. (D) The body weight changes of the mice were recorded during the experimental period. (E) The formed tumors were obtained for TUNEL staining after the 2 Ist day of capsaicin treatment (scale bar I00 $\mu \mathrm{m}$ ). The TUNEL positive cells were quantified by using Image-Pro Plus 5.0 software. Data are presented as means $\pm \mathrm{SD},{ }^{*} p<0.05$ vs Control; ${ }^{2} p<0.05$ vs Capsaicin. (F) The protein levels of FBI-I, Ki- 67 , $\mathrm{Bcl}-2$, Bax, cleaved-Caspase 3 and Survivin in final formed tumor tissues were detected by Western blot. Data are presented as means \pm SD, ${ }^{*} p<0.05$ vs Control; ${ }^{*}<<0.05$ vs Capsaicin.

our findings, other studies provided evidence that capsaicin displayed no apparent toxicity in animals. ${ }^{32,33}$ Taken together, all of the above findings suggest the potential role in the treatment of breast cancer with anti-cancer activity and no unwanted side effects.

Furthermore, we demonstrated that FBI-1 was a target of capsaicin in breast cancer, and this might explain some of the mechanisms whereby capsaicin elicited its benefits. FBI-1 is one of the transcriptional suppressors belonging to POK family. It was first identified as a protein specifically binding to the inducer of short transcript on the HIV1 promoter. ${ }^{16,34}$ Previous studies have shown that FBI-1 could stimulate TAT activity of HIV, increase NF- $\mathrm{kB}$ mediated transcription, and suppress the expression of human ADH5/FDH5 gene. ${ }^{15,35-37}$ There is evidence that FBI-1 acts as an important proto-oncogene, and aberrantly overexpressed in multiple human cancers such as lymphoma, lung cancer, breast cancer, prostate cancer, colon cancer and bladder cancer. ${ }^{15,16}$ The mouse embryonic fibroblasts (MEFs) deficient in FBI-1 are refractory to oncogenic transformation. On the contrary, FBI-1 overexpression leads to obvious oncogenic transformation of MEFs. ${ }^{16}$ Recently, Zhu et al reported that silencing of
FBI-1 significantly suppressed proliferation of hepatocellular carcinoma cells and enhanced cisplatin-induced apoptosis. ${ }^{38}$ Yuan et al found that the growth of tumors was significantly inhibited and the survival time of mice significantly prolonged when treated with endoplasmic reticulum chaperone glucose regulated protein 170-FBI-1 complex. ${ }^{39}$ Mak et al found that the FBI-1 silencing inhibited proliferation, migration and invasion, and promoted apoptosis of choriocarcinoma cells. ${ }^{40}$ It has also been reported that FBI-1 knockdown suppresses proliferation, arrests cell cycle and promotes apoptosis in prostate cancer. ${ }^{41}$ Some evidence has indicated that the expression of FBI-1 in breast cancer tissues also exhibits significantly higher than that in normal tissues and benign breast disease tissues, which is consistently correlated to the poor prognosis, ${ }^{20,21,22}$ and antagonizing FBI-1 could suppress proliferation, arrest cell cycle and promote apoptosis of breast cancer cells. ${ }^{22,42,43}$ Consequently, our recent study also confirmed that abnormally high expression of FBI-1 was noted in breast cancer tissues and breast cancer cell lines MCF-7 as well as MDA-MB-231. Besides, FBI-1 overexpression promoted migration, invasion and metastasis, while FBI-1 silencing generated the opposite 
MCF-7
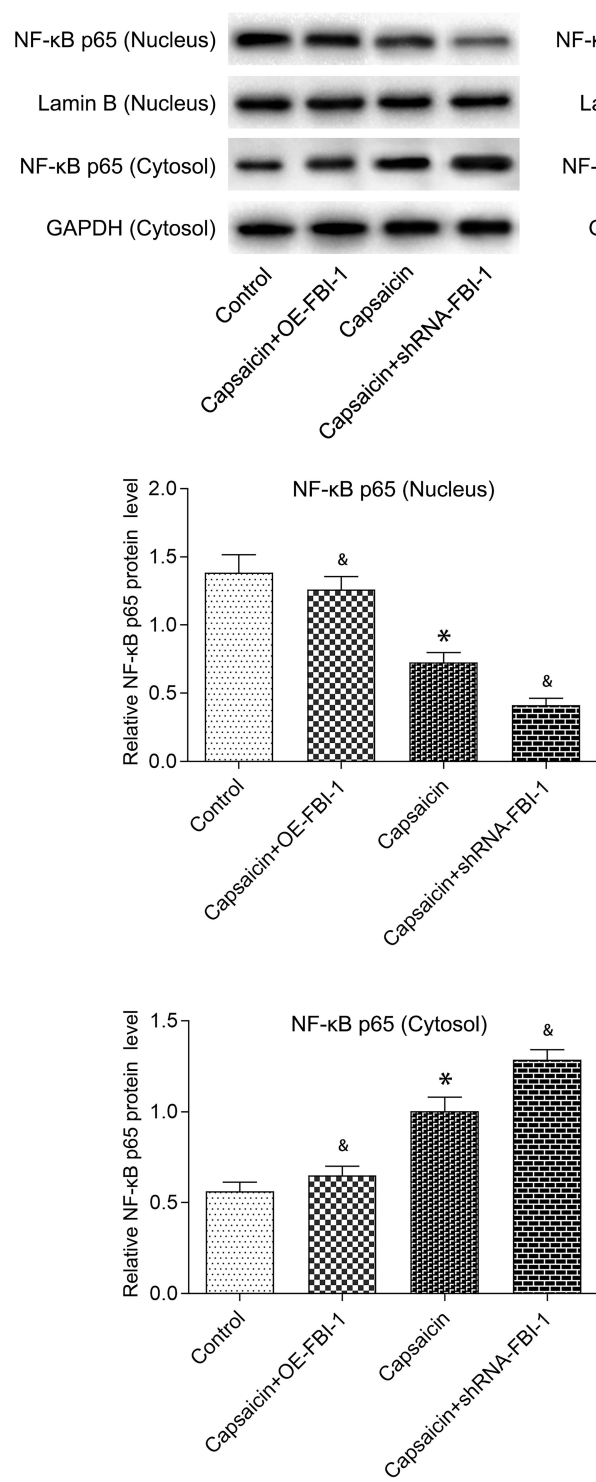

MDA-MB-231
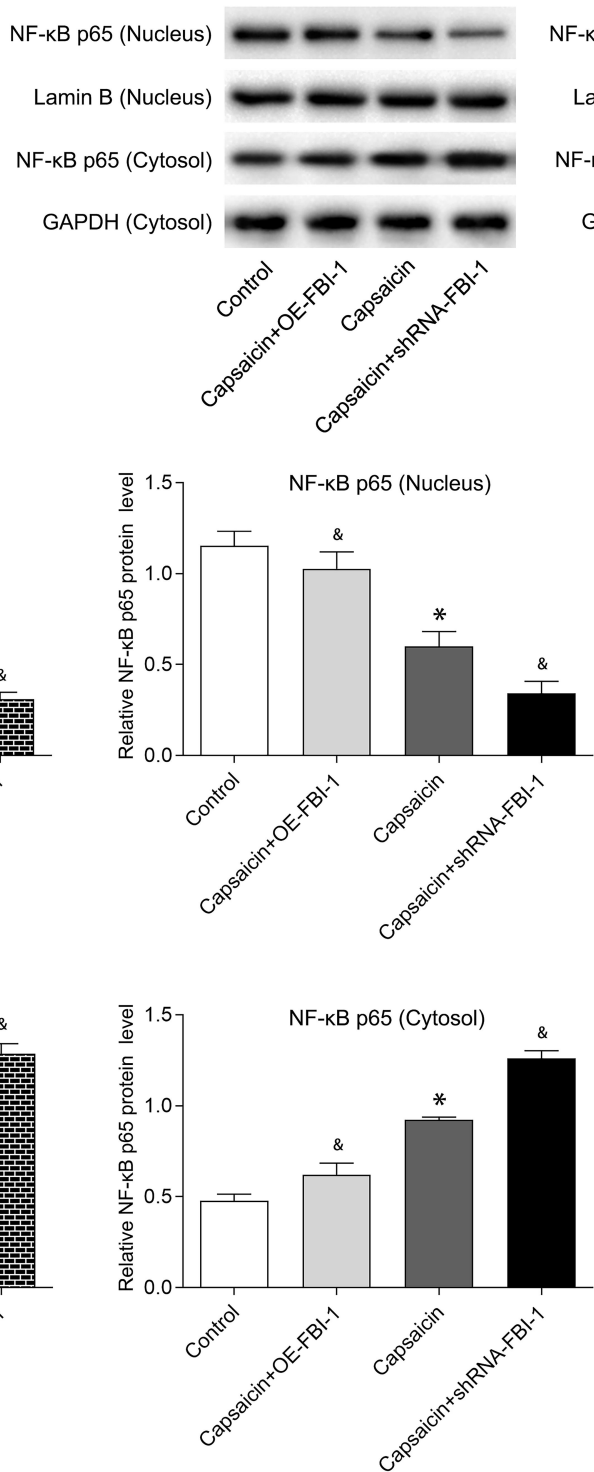

Formed tumor tissue
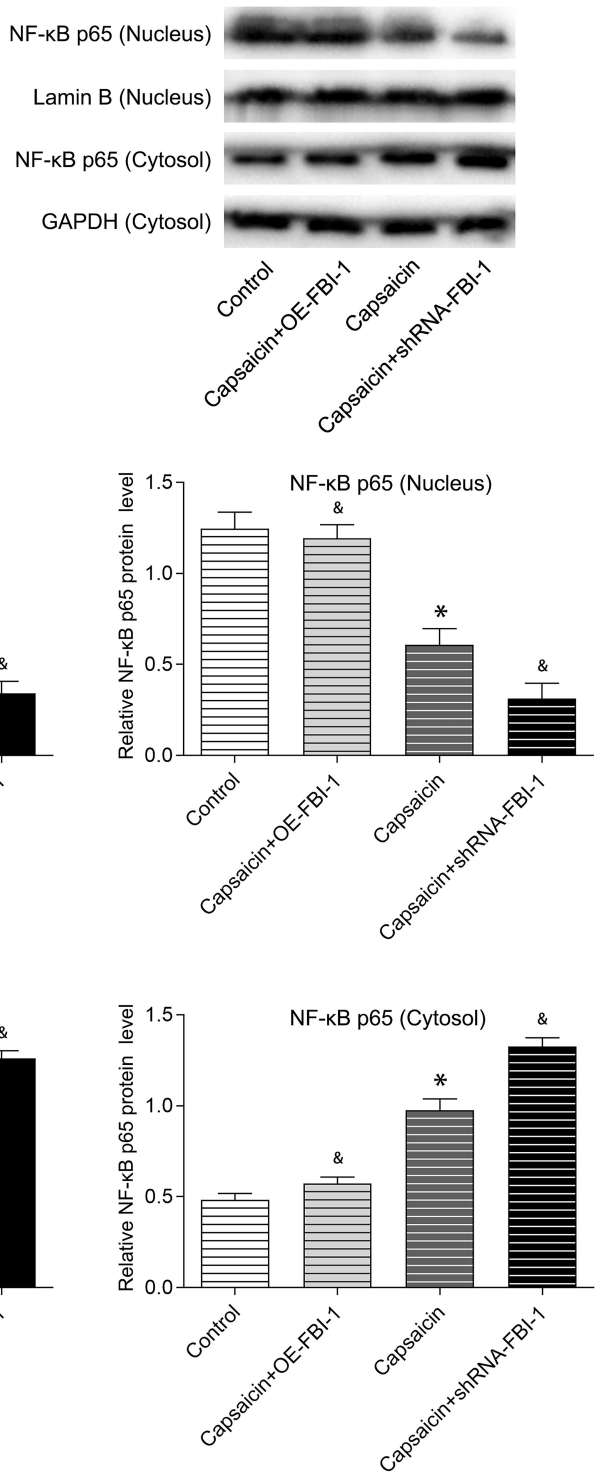

Figure 8 Capsaicin-induced $\mathrm{FBI}-\mathrm{I}$ down-regulation suppresses NF- $\mathrm{KB}$ activation in breast cancer in vitro and in vivo. NF- $\mathrm{B}$ activity by Western blot analysis of NF- $\mathrm{KB}$ p65 level in nuclear and cytoplasm with capsaicin (in vitro: $150 \mu \mathrm{mol} / \mathrm{L}$ for $72 \mathrm{~h}$; in vivo: $10 \mathrm{mg} / \mathrm{kg}$, once in three days for 21 days) treatment alone or together with $\mathrm{FBI}-\mathrm{I}$ overexpression or silencing. Data are presented as means $\pm S D, * p<0.05$ vs Control; ${ }^{\&} p<0.05$ vs Capsaicin.

effects. ${ }^{23}$ In this study, we further demonstrated that FBI-1 overexpression promoted proliferation and repressed apoptosis of breast cancer, while FBI-1 silencing inhibited proliferation and induced apoptosis. All these findings suggest that FBI-1 may be an effective new target for the prevention and treatment in breast cancer.

Given the fact that FBI-1 is closely involved in the occurrence and development of breast cancer, we explored the effect of capsaicin on FBI-1 expression in breast cancer. As expected, the expression of FBI-1 was suppressed with capsaicin treatment. Strikingly, the capsaicin-induced anti-proliferation and pro-apoptosis effects in breast cancer were perceptibly weakened with FBI-1 overexpression or enhanced with FBI-1 silencing. Based on these promising results, we further examined the typical reported downstream targets of FBI-1 involving in proliferation and apoptosis. As well-known, Ki-67 is a widely accepted marker reflecting the proliferation of tumor cells, which predicts prognosis of breast cancer. ${ }^{44,45} \mathrm{Bcl}-2$ and Bax are the most representative genes strictly associated with apoptosis in the Bcl-2 family. ${ }^{46}$ The interaction of Bax and Bcl-2 balances the pro- or anti-apoptotic activity, which is closely related to tumor occurrence and development. ${ }^{46,47}$ As the core protease in the protease 
cascade reaction to activate apoptosis, the activated caspase-3 is considered to be the executor of apoptosis. ${ }^{48}$ Survivin, the most powerful inhibitor in the inhibitor of apoptosis protein family, is able to directly suppress caspase-3 in the core of apoptotic pathway to inhibit cellular apoptosis. ${ }^{49}$ The inhibition of pro-apoptotic genes and the activation of anti-apoptotic genes lead to unlimited proliferation of tumor cells and the maintenance of immortal cells, which drive tumorigenesis and progression. ${ }^{50}$ It has been reported that FBI-1 knockdown promotes apoptosis in hepatocellular carcinoma, accompanied by increased Bax expression and decreased Bcl-2 expression. ${ }^{51,52}$ Zhang et al reported that the FBI-1 silencing promoted caspase-dependent apoptosis through Fas- and mitochondrial-mediated pathways in hepatocellular carcinoma. ${ }^{52} \mathrm{Zu}$ et al found that survivin was one of the target genes of FBI-1, FBI-1 promoted breast cancer progression by upregulating the expression of Survivin. ${ }^{22}$ Along these lines, our further study found that FBI-1 overexpression significantly up-regulated the expression of $\mathrm{Ki}-67, \mathrm{Bcl}-2$ and Survivin, and down-regulated the expression of Bax and cleaved-caspase 3. Conversely, FBI-1 silencing generated opposite effects. In addition, despite capsaicin treatment significantly suppressed the expression of Ki-67, Bcl-2 and Survivin, and promoted the expression of Bax and cleaved-caspase 3 , such effects were perceptibly weakened with FBI-1 overexpression or enhanced with FBI-1 silencing. Similar results were also observed in vivo study. Altogether, these findings provide evidence demonstrating that capsaicin exhibits anti-proliferation and pro-apoptosis activities in breast cancer may through targeting FBI- 1 and thus modulate its reported downstream proliferation- and apoptosis-related proteins.

Nuclear factor kappa B (NF-kB) is widely accepted as an important transcription regulatory factor with a variety of transcriptional regulatory activities. As the intersection of multiple signal pathways, NF- $\mathrm{KB}$ regulates multiple genes expression involving in proliferation, apoptosis, invasion and metastasis, etc., and plays a key role in the process of tumorigenesis and progression. ${ }^{53,54}$ Aberrant activation of $\mathrm{NF}-\mathrm{\kappa B}$ has been confirmed to promote proliferation and inhibit apoptosis in malignant cells. ${ }^{55,56}$ It has been proven that NF- $\mathrm{kB}$ is the downstream target gene of FBI-1, FBI-1 could promote the nuclear localization and stability of NF-kB p65, which enhance the transcriptional activity of NF- $\mathrm{kB} .{ }^{35,51,57,58} \mathrm{~A}$ recent report uncovered that FBI-1 silencing down-regulated the expression of Bcl-2 through targeting NF- $\kappa \mathrm{B}$ pathway, and thus promoted apoptosis in hepatocellular carcinoma. ${ }^{51}$ Our previous study also found that FBI-1 promoted migration, invasion and metastasis of breast cancer through NF- $\mathrm{KB}$-induced epithelial-mesenchymal transition. ${ }^{23}$ In this study, we revealed that capsaicin significantly suppressed NF- $\mathrm{KB}$ activation by inhibiting p65 nuclear translocation in vitro and in vivo, which was significantly weakened with FBI-1 overexpression or enhanced with FBI-1 silencing. However, with accumulating evidence indicating the dual roles of NF- $\mathrm{KB}$ in cancer development including inducing and blocking apoptosis, pleiotropic effects of capsaicin on NF- $\kappa \mathrm{B}$ are reported and have raised much debate. ${ }^{59,60,61}$ For example, in malignant melanoma, cholangiocarcinoma and lung cancer, capsaicin was found to suppress NF- $\kappa B$ activation. ${ }^{61-64}$ while recently, capsaicin was reported to induce NF- $\kappa \mathrm{B}$ activity in colorectal cancer and esophagus squamous cell carcinoma. ${ }^{29,65}$ We speculated that the pleiotropic effects of capsaicin on NF- $\kappa \mathrm{B}$ varied according to different roles of NF- $\mathrm{KB}$ in different cancer types, future studies with focus to clarify this issue would be necessary. Nevertheless, our present findings suggest that capsaicin inhibits proliferation and induces apoptosis in breast cancer possibly through down-regulating FBI-1mediated NF- $\mathrm{BB}$ pathway, which may ultimately

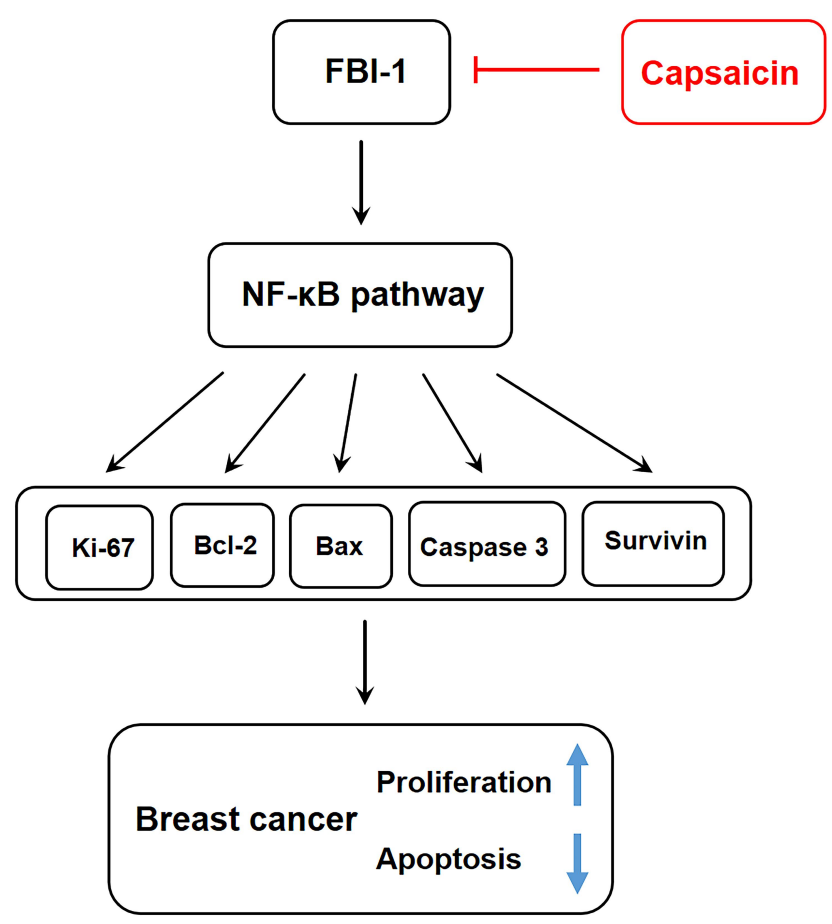

Figure 9 Schematic diagram of possible action mechanism of capsaicin on proliferation and apoptosis in breast cancer. 
modulate its reported downstream targets ${ }^{66-68}$ including Ki-67, Bcl-2, Bax, cleaved-caspase 3 and Survivin proteins (Figure 9).

\section{Conclusion}

In conclusion, this study reveals that FBI-1 is closely involved in capsaicin-induced proliferation inhibition and apoptosis promotion in breast cancer. The underlying mechanism may be related to down-regulation of FBI-1mediated NF- $\kappa$ B pathway. Targeting FBI-1 with capsaicin may be a promising therapeutic strategy in patients with breast cancer.

\section{Acknowledgments}

This work was carried out with the supports of the National Natural Science Foundation of China (No. 81360396, 81860341), the International Communication of Guangxi Medical University Graduate Education, the Science and Technology Infrastructure Project of Guangxi (No.15-23505), the Natural Science Foundation of Guangxi (No. 2019GXNSFAA245067, 2020JJA140036) and the Innovation Project of Guangxi Graduate Education (No. YCSW2017108, YCBZ2018041).

\section{Disclosure}

The authors declare that there are no conflicts of interest.

\section{References}

1. DeSantis CE, Ma JM, Gaudet MM, et al. Breast cancer statistics, 2019. CA Cancer J Clin. 2019;69(6):438-451. doi:10.3322/caac.21583

2. Harbeck N, Penault-Llorca F, Cortes J, et al. Breast cancer. Nat Rev Dis Primers. 2019;5(1):66. doi:10.1038/s41572-019-0111-2

3. Yun TK. Update from Asia: asian Studies on Cancer Chemoprevention. Ann $N \quad Y$ Acad Sci. 1999;889:157-192. doi:10.1111/j.1749-6632.1999.tb08734.x

4. Chapa-Oliver AM, Mejia-Teniente L. Capsaicin: from Plants to a Cancer-Suppressing Agent. Molecules. 2016;21(8):931. doi:10.3390/ molecules21080931

5. Bort A, Sanchez BG, Spinola E, Mateos-Gomez PA, RodriguezHenche N, Diaz-Laviada I. The red pepper's spicy ingredient capsaicin activates AMPK in HepG2 cells through CaMKK $\beta$. PLoS One. 2019;14(1):e0211420. doi:10.1371/journal.pone.0211420

6. Sharma SK, Vij AS, Sharma M. Mechanisms and clinical uses of capsaicin. Eur J Pharmacol. 2013;720(1-3):55-62. doi:10.1016/j. ejphar.2013.10.053

7. Fattori V, Hohmann MS, Rossaneis AC, Pinho-Ribeiro FA, Verri WA. Capsaicin: current Understanding of Its Mechanisms and Therapy of Pain and Other Pre-Clinical and Clinical Uses. Molecules. 2016;21: (7):844. doi:10.3390/molecules21070844

8. Clark R, Lee SH. Anticancer Properties of Capsaicin Against Human Cancer. Anticancer Res. 2016;36(3):837-843. PMID: 26976969

9. Zhang SP, Wang D, Huang JY, Hu YM, Xu YF. Application of capsaicin as a potential new therapeutic drug in human cancers. $J$ Clin Pharm Ther. 2020;45(1):16-28. doi:10.1111/jcpt.13039
10. Minke B. TRP channels and Ca2+ signaling. Cell Calcium. 2006;40 (3):261-275. doi:10.1016/j.ceca.2006.05.002

11. Yang ZH, Wang XH, Wang HP, Hu LQ, Zheng XM, Li SW. Capsaicin mediates cell death in bladder cancer T24 cells through reactive oxygen species production and mitochondrial depolarization. Urology. 2010;75(3):735-741. doi:10.1016/j.urology.2009.03.042

12. Sanchez AM, Sanchez MG, Malagarie-Cazenave S, Olea N, DiazLaviada I. Induction of apoptosis in prostate tumor PC-3 cells and inhibition of xenograft prostate tumor growth by the vanilloid capsaicin. Apoptosis. 2006;11(1):89-99. doi:10.1007/s10495-005-3275-Z

13. Stogios PJ, Chen L, Prive GG. Crystal structure of the BTB domain from the LRF/ZBTB7 transcriptional regulator. Protein Sci. 2006;16 (2):336-342. doi:10.1110/ps.062660907

14. Liu XS, Genet MD, Haines JE, et al. ZBTB7A Suppresses Melanoma Metastasis by Transcriptionally Repressing MCAM. Mol Cancer Res. 2015;13(8):1206-1217. doi:10.1158/1541-7786.MCR-15-0169

15. Maeda T, Hobbs RM, Merghoub T, et al. Role of the proto-oncogene Pokemon in cellular transformation and ARF repression. Nature. 2005;433(7023):278-285. doi:10.1038/nature03203

16. Maeda T, Hobbs RM, Pandolfi PP. The transcription factor pokemon: a new key player in cancer pathogenesis: figure 1. Cancer Res. 2005;65(19):8575-8578. doi:10.1158/0008-5472.CAN-05-1055

17. Jeon BN, Yoo JY, Choi WI, Lee CE, Yoon HG, Hur MW. Protooncogene FBI-1 (Pokemon/ZBTB7A) Represses Transcription of the Tumor suppressor RB gene via binding competition with $\mathrm{sp} 1$ and recruitment of co-repressors. J Biol Chem. 2008;283(48):3319933210. doi:10.1074/jbc.M802935200

18. Choi WI, Jeon BN, Yun CO, et al. Proto-oncogene FBI-1 Represses Transcription of $\mathrm{p} 21 \mathrm{CIP} 1$ by Inhibition of Transcription Activation by p53 and Sp1. J Biol Chem. 2009;284(19):12633-12644. doi:10.1074/jbc.M809794200

19. Yang YT, Cui JJ, Xue F, et al. Resveratrol represses pokemon expression in human glioma cells. Mol Neurobiol. 2016;53 (2):1266-1278. doi:10.1007/s12035-014-9081-2

20. Qu HY, Qu DN, Chen FH, Zhang ZY, Liu BG, Liu HF. ZBTB7 overexpression contributes to malignancy in breast cancer. Cancer Invest. 2010;28(6):672-678. doi:10.3109/07357901003631007

21. Aggarwal A, Hunter WJ, Aggarwal H, et al. Expression of leukemia/ lymphoma-related factor (LRF/POKEMON) in human breast carcinoma and other cancers. Exp Mol Pathol. 2010;89(2):140-148. doi:10.1016/j.yexmp.2010.05.002

22. Zu XY, Ma J, Liu HX, et al. Pro-oncogene Pokemon promotes breast cancer progression by upregulating survivin expression. Breast Cancer Res. 2011;13(2):R26. doi:10.1186/bcr2843

23. Mao AY, Chen MJ, Qin QH, et al. ZBTB7A promotes migration, invasion and metastasis of human breast cancer cells through NF- $\mathrm{kB}-$ induced epithelial-mesenchymal transition in vitro and in vivo. $J$ Biochem. 2019;166(6):485-493. doi:10.1093/jb/mvz062

24. Anandakumar P, Kamaraj S, Jagan S, Ramakrishnan G, Devaki T. Capsaicin provokes apoptosis and restricts benzo(a)pyrene induced lung tumorigenesis in Swiss albino mice. Int Immunopharmacol. 2013;17(2):254-259. doi:10.1016/j.intimp.2013.05.015

25. Li Y, Li S, Meng X, Gan RY, Zhang JJ, Li HB. Dietary natural products for prevention and treatment of breast cancer. Nutrients. 2017;9(7):728. doi:10.3390/nu9070728

26. Zhu MM, Yu X, Zheng ZM, Huang JM, Yang XP, Shi HF. Capsaicin suppressed activity of prostate cancer stem cells by inhibition of Wnt $/ \beta$ catenin pathway. Phytother Res. 2020;34(4):817-824. doi:10.1002/ptr.6563

27. Islam A, Yang YT, Wu WH, Chueh PJ, Lin MH. Capsaicin attenuates cell migration via SIRT1 targeting and inhibition to enhance cortactin and $\beta$-catenin acetylation in bladder cancer cells. Am J Cancer Res. 2019;9(6):1172-1182. PMID: 31285950

28. Qian KY, Wang G, Cao R, et al. Capsaicin suppresses cell proliferation, induces cell cycle arrest and ros production in bladder cancer cells through FOXO3A-mediated pathways. Molecules. 2016;21 (10):1406. doi:10.3390/molecules21101406 
29. Clark R, Lee J, Lee SH. Synergistic Anticancer activity of capsaicin and 3,3'-diindolylmethane in human colorectal cancer. J Agric Food Chem. 2015;63(17):4297-4304. doi:10.1021/jf506098s

30. Yang KM, Pyo JO, Kim GY, et al. Capsaicin induces apoptosis by generating reactive oxygen species and disrupting mitochondrial transmembrane potential in human colon cancer cell lines. Cell Mol Biol Lett. 2009;14(3):497-510. doi:10.2478/s11658-009-0016-2

31. Chou CC, Wu YC, Wang YF, Chou MJ, Kuo SJ, Chen D-R. Capsaicin-induced apoptosis in human breast cancer MCF-7 cells through caspase-independent pathway. Oncol Rep. 2009;21(3):665671. PMID: 19212624

32. Thoennissen NH, O'Kelly J, Lu D, et al. Capsaicin causes cell-cycle arrest and apoptosis in ER-positive and -negative breast cancer cells by modulating the EGFR/HER-2 pathway. Oncogene. 2010;29 (2):285-296. doi:10.1038/onc.2009.335

33. Ito $\mathrm{K}$, Nakazato $\mathrm{T}$, Yamato $\mathrm{K}$, et al. Induction of apoptosis in leukemic cells by homovanillic acid derivative, capsaicin, through oxidative stress: implication of phosphorylation of p53 at Ser-15 residue by reactive oxygen species. Cancer Res. 2004;64(3):10711078. doi:10.1158/0008-5472.CAN-03-1670

34. Pessler F, Pendergrast PS, Hernandez N. Purification and characterization of FBI-1, a cellular factor that binds to the human immunodeficiency virus type 1 inducer of short transcripts.. Mol Cell Biol. 1997;17(7):3786-3798. doi:10.1128/MCB.17.7.3786

35. Lee DK, Kang JE, Park HJ, et al. FBI-1 Enhances Transcription of the Nuclear Factor- $\kappa \mathrm{B}(\mathrm{NF}-\kappa \mathrm{B})$-responsive E-selectin Gene by Nuclear Localization of the p65 Subunit of NF-кB. J Biol Chem. 2005;280(30):27783-27791. doi:10.1074/jbc.M504909200

36. Lee DK, Suh D, Edenberg HJ, Hur MW. POZ Domain Transcription Factor, FBI-1, Represses Transcription of ADH5/FDH by Interacting with the Zinc Finger and Interfering with DNA Binding Activity of Sp1. J Biol Chem. 2002;277(30):26761-26768. doi:10.1074/jbc.M202078200

37. Pendergrast PS, Wang C, Hernandez N, Huang S. FBI-1 Can Stimulate HIV-1 Tat Activity and Is Targeted to a Novel Subnuclear Domain that Includes the Tat-P-TEFb-containing Nuclear Speckles. Mol Biol Cell. 2002;13(3):915-929. doi:10.1091/ mbc.01-08-0383

38. Zhu XS, Dai YC, Chen ZX, Xie JP, Zeng W, Lin YY. Knockdown of Pokemon protein expression inhibits hepatocellular carcinoma cell proliferation by suppression of AKT activity. Oncol Res. 2013;20 (8):377-381. doi:10.3727/096504013X13657689383012

39. Yuan BQ, Xian RH, Wu XQ, et al. Endoplasmic reticulum chaperone glucose regulated protein 170-Pokemon complexes elicit a robust antitumor immune response in vivo. Immunobiology. 2012;217 (7):738-742. doi:10.1016/j.imbio.2012.01.006

40. Mak VCY, Wong OGW, Siu MKY, et al. FBI-1 Is Overexpressed in Gestational Trophoblastic Disease and Promotes Tumor Growth and Cell Aggressiveness of Choriocarcinoma via PI3K/Akt Signaling. Am J Pathol. 2006;16(2):2038-2048. doi:10.1016/j. ajpath.2015.03.011

41. Jiang FQ, Zheng QF, Chang LP, Li X, Wang XS, Gu XQ. Prooncogene Pokemon Promotes Prostate Cancer Progression by Inducing STRN4 Expression. J Cancer. 2019;10(8):1833-1845. doi:10.7150/jca.29471

42. Chen L, Zhong J, Liu JH, et al. Pokemon Inhibits Transforming Growth Factor $\beta$-Smad4-Related Cell Proliferation Arrest in Breast Cancer through Specificity Protein 1. J Breast Cancer. 2019;22 (1):15-28. doi:10.4048/jbc.2019.22.e11

43. Xiao X, Shen YY, Yin LY, et al. Knockdown of ZBTB7A inhibits cell proliferation of breast cancer through regulating the ubiquitination of estrogen receptor alpha. Life Sci. 2019;239:117042. doi:10.1016/j. lfs.2019.117042

44. Niazi MKK, Senaras C, Pennell M, Arole V, Tozbikian G, Gurcan MN. Relationship between the Ki67 index and its area based approximation in breast cancer. BMC Cancer. 2018;18(1):867. doi:10.1186/ s12885-018-4735-5
45. Cabrera-Galeana P, Muñoz-Montaño W, Lara-Medina F, et al. Ki67 Changes Identify Worse Outcomes in Residual Breast Cancer Tumors After Neoadjuvant Chemotherapy. Oncologist. 2018;23(6):670-678. doi:10.1634/theoncologist.2017-0396

46. Brady HJ, Gil-Gómez G. Molecules in focus Bax. The pro-apoptotic Bcl-2 family member, Bax. Int J Biochem Cell Biol. 1998;30(6):647650. doi:10.1016/S1357-2725(98)00006-5

47. Del Poeta G, Venditti A, Del Principe MI, et al. Amount of spontaneous apoptosis detected by $\mathrm{Bax} / \mathrm{Bcl}-2$ ratio predicts outcome in acute myeloid leukemia (AML). Blood. 2003;101(6):2125-2131. doi:10.1182/blood-2002-06-1714

48. Porter AG, Jänicke RU. Emerging roles of caspase-3 in apoptosis. Cell Death Differ. 1999;6(2):99-104. doi:10.1038/sj.cdd.4400476

49. LaCasse EC, Baird S, Korneluk RG, MacKenzie AE. The inhibitors of apoptosis (IAPs) and their emerging role in cancer. Oncogene. 1998;17(25):3247-3259. doi:10.1038/sj.onc.1202569

50. Fulda S, Targeting VD. IAP proteins for therapeutic intervention in cancer. Nat Rev Drug Discov. 2012;11(2):109-124. doi:10.1038/ $\operatorname{nrd} 3627$

51. Zhao XK, Ning QM, Sun XN, Tian DA. Pokemon reduces Bcl-2 expression through NF-kappa Bp65: A possible mechanism of hepatocellular carcinoma. Asian Pac J Trop Med. 2011;4(6):492-497. doi:10.1016/S1995-7645(11)60133-8

52. Zhang YQ, Xiao CX, Lin BY, et al. Silencing of Pokemon enhances caspase-dependent apoptosis via fas- and mitochondria-mediated pathways in hepatocellular carcinoma cells. PLoS One. 2013;8(7):e68981. doi:10.1371/journal.pone.0068981

53. Hoesel B, Schmid JA. The complexity of NF-kappaB signaling in inflammation and cancer. Mol Cancer. 2013;12:86. doi:10.1186/ 1476-4598-12-86

54. Xia YF, Shen S, Verma IM. NF-kappaB, an active player in human cancers. Cancer Immunol Res. 2014;2(9):823-830. doi:10.1158/ 2326-6066.CIR-14-0112

55. Beg AA, Baltimore D. An essential role for NF-kappaB in preventing TNF-alpha-induced cell death. Science. 1996;274(5288):782-784. doi:10.1126/science.274.5288.782

56. Wang CY, Mayo MW, Korneluk RG, Goeddel DV, Baldwin ASJ. NFkappaB antiapoptosis: induction of TRAF1 and TRAF2 and c-IAP1 and c-IAP2 to suppress caspase-8 activation. Science. 1998;281 (5383):1680-1683. doi:10.1126/science.281.5383.1680

57. Zhang NN, Sun QS, Chen Z, Liu F, Jiang YY. Homeostatic regulatory role of Pokemon in NF-kappaB signaling: stimulating both p65 and IkappaBalpha expression in human hepatocellular carcinoma cells. Mol Cell Biochem. 2013;372(1-2):57-64. doi:10.1007/ s11010-012-1445-1

58. Ramos Pittol JM, Oruba A, Mittler G, Saccani S, van Essen D. $\mathrm{Zbtb} 7 \mathrm{a}$ is a transducer for the control of promoter accessibility by NF-kappa B and multiple other transcription factors. PLoS Biol. 2018;16(5):e2004526. doi:10.1371/journal.pbio.2004526

59. Lee $\mathrm{CH}$, Jeon YT, Kim SH, Song YS. NF-kappaB as a potential molecular target for cancer therapy. Biofactors. 2007;29(1):19-35. doi:10.1002/biof.5520290103

60. Perkins ND. The diverse and complex roles of NF- $\kappa B$ subunits in cancer. Nat Rev Cancer. 2012;12(2):121-132. doi:10.1038/nrc3204

61. Surh YJ. Cancer chemoprevention with dietary phytochemicals. Nat Rev Cancer. 2003;3(10):768-780. doi:10.1038/nrc1189

62. Patel PS, Varney ML, Dave BJ, Singh RK. Regulation of constitutive and induced NF-kappaB activation in malignant melanoma cells by capsaicin modulates interleukin-8 production and cell proliferation. $J$ Interferon Cytokine Res. 2002;22(4):427-435. doi:10.1089/ 10799900252952217

63. Lee GR, Jang SH, Kim CJ, et al. Capsaicin suppresses the migration of cholangiocarcinoma cells by down-regulating matrix metalloproteinase-9 expression via the AMPK-NF- $\kappa$ B signaling pathway. Clin Exp Metastasis. 2014;31(8):897-907. doi:10.1007/s10585-0149678-x 
64. Anandakumar P, Kamaraj S, Jagan S, et al. Capsaicin inhibits benzo (a)pyrene-induced lung carcinogenesis in an in vivo mouse model. Inflamm Res. 2012;61(11):1169-1175. doi:10.1007/s00011-0120511-1

65. Guo Y, Liu N, Liu K, Gao M. Capsaicin inhibits the migration and invasion via the $\mathrm{AMPK} / \mathrm{NF}-\kappa \mathrm{B}$ signaling pathway in esophagus sequamous cell carcinoma by decreasing matrix metalloproteinase- 9 expression. Biosci Rep. 2019;39(8):BSR20190819. doi:10.1042/ BSR20190819

66. Wang YW, Zhou YN, Jia G, et al. Shikonin suppresses tumor growth and synergizes with gemcitabine in a pancreatic cancer xenograft model: involvement of $\mathrm{NF}-\kappa \mathrm{B}$ signaling pathway. Biochem Pharmacol. 2014;88(3):322-333. doi:10.1016/j.bcp.2014.01.041
67. Xu B, Zhang AM, Li F, Cui M, Han J, Cao Q. XZ-1 regulates cell apoptosis of gastric epithelial dysplasia via NF- $\mathrm{kB} / \mathrm{p} 53 / \mathrm{Ki} 67$ signaling pathway. Biosci Rep. 2018;38(3):BSR20171529. doi:10.1042/ BSR20171529

68. Karin M. Nuclear factor-kappaB in cancer development and progression. Nature. 2006;441(7092):431-436. doi:10.1038/nature04870

\section{Publish your work in this journal}

Drug Design, Development and Therapy is an international, peerreviewed open-access journal that spans the spectrum of drug design and development through to clinical applications. Clinical outcomes, patient safety, and programs for the development and effective, safe, and sustained use of medicines are a feature of the journal, which has also been accepted for indexing on PubMed Central. The manuscript management system is completely online and includes a very quick and fair peer-review system, which is all easy to use. Visit http://www. dovepress.com/testimonials.php to read real quotes from published authors. 